\title{
The role of oviduct-specific glycoprotein (OVGP1) in modulating biological functions of gametes and embryos
}

\author{
Yuewen Zhao ${ }^{1,2} \cdot$ Sydney Vanderkooi ${ }^{1} \cdot$ Frederick W. K. Kan $^{1}$ (i)
}

Accepted: 8 December 2021 / Published online: 6 January 2022

(c) The Author(s) 2021

\begin{abstract}
Diverse lines of evidence indicate that the mammalian oviduct makes important contributions to the complex process of reproduction other than being simply a conduit for the transport of gametes and embryos. The cumulative synthesis and transport of proteins secreted by oviductal secretory cells into the oviductal lumen create a microenvironment supporting important reproductive events, including sperm capacitation, fertilization, and early embryo development. Among the components that have been identified in the oviductal fluid is a family of glycosylated proteins known collectively as oviductspecific glycoprotein (OVGP1) or oviductin. OVGP1 has been identified in several mammalian species, including humans. The present review summarizes the work carried out, in various mammalian species, by many research groups revealing the synthesis and secretion of OVGP1, its fate in the female reproductive tract upon secretion by the oviductal epithelium, and its role in modulating biological functions of gametes and embryos. The production and functions of recombinant human OVGP1 and recombinant OVGP1 of other mammalian species are also discussed. Some of the findings obtained with immunocytochemistry will be highlighted in the present review. It is hoped that the findings obtained from recent studies carried out with recombinant OVGP1 from various species will rekindle researchers' interest in pursuing further the role of the oviductal microenvironment, of which OVGP1 is a major component, in contributing to the successful occurrence of early reproductive events, and the potential use of OVGP1 in improving the current assisted reproductive technology in alleviating infertility.
\end{abstract}

Keywords Oviduct-specific glycoprotein · Oviductin · OVGP1 · Fertilization · Sperm-egg binding · Oviductal fluid

\section{Introduction}

The mammalian oviductal fluid consists of a complex mixture originating from plasma transudation and glycoproteins secreted by oviduct epithelial cells (Aviles et al. 2010). The oviductal fluid in the lumen of mammalian oviducts provides a suitable milieu for gamete maturation and fertilization. Freshly ejaculated sperm are motile, but they have to undergo a series of physiological changes,

Frederick W. K. Kan

kanfwk@queensu.ca

1 Department of Biomedical and Molecular Sciences, Faculty of Health Sciences, Queen's University, Kingston, ON K7L 3N, Canada

2 Present Address: Division of Reproductive Endocrinology and Infertility, Department of Obstetrics, Gynecology and Reproductive Sciences, Yale Fertility Center, Yale University, Orange, CT 06477, USA collectively known as capacitation, to become fertilizing competent (Molina et al. 2018). In the in vivo condition, sperm that have reached and resided in the oviducts acquire the maximum level of fertilizing capacity. Therefore, the microenvironment of the oviductal lumen and the molecular components of oviductal fluid play an essential role in the early events of fertilization. Currently, culture media used in fertility clinics and research laboratories mimicking the physiological condition of oviductal fluid have made in vitro fertilization (IVF) possible for fertility treatments in the clinical setting, and for research purposes. Today, the global infertility rate is about $15 \%$ among couples who try to have a child but the woman fails to conceive. Infertile couples often seek assisted reproduction as a treatment. However, total fertilization failure occurs in 5-15\% of couples undergoing conventional IVF despite having normal sperm quality (van der Westerlaken et al. 2005). Intracytoplasmic sperm injection (ICSI) procedure was introduced as a treatment for unexplained fertilization failure or low fertilization rate after 
conventional IVF (van der Westerlaken et al. 2005). ICSI is a relatively invasive procedure, and accumulating findings reported in literature have linked the association of ICSI with increased congenital disability rates compared with natural birth (Bushnik et al. 2012; Simpson 2014). Given the potential adverse effects of ICSI on the offspring, investigations into improving the success rate of conventional IVF are warranted to encourage infertile patients with mild male factor to seek the less invasive conventional IVF for treatment.

It has been suggested that oviduct-specific glycoprotein, also known as OVGP1 or oviductin, can be added as a supplement to capacitating media currently used in assisted reproductive technology (ART) procedures in fertility clinics to improve the success rate of IVF (Aviles et al. 2010). The present review provides an overview of the identification and characterization of OVGP1 and its functions, particularly its role in fertilization and early embryo development in various mammalian species, including humans. At the end of the review, the production of recombinant human OVGP1 and other recombinant OVGP1s as well as their functions are also discussed. Among the various techniques that were employed to study the properties and functions of OVGP1, immunocytochemistry at both the light and electron microscopic levels has been an important investigative tool used in conjunction with other techniques in contributing to our knowledge and understanding of the synthesis, secretion, sites of localization, and functions of mammalian OVGP1. Some of the findings obtained with immunocytochemistry will be highlighted in the present review.

\section{Prologue}

The mammalian oviduct occupies a strategic site in the female reproductive tract where fertilization takes place. The oviduct provides a suitable milieu in its lumen for many early events of reproduction to take place. The oviduct secretes many proteins, among which is a family of highly glycosylated protein named oviduct-specific glycoprotein, also known as OVGP1 or oviductin, which is exclusively synthesized and secreted by nonciliated secretory cells in the oviductal epithelium (Fig. 1). Since the discovery in hamster that the oviduct-derived glycoprotein was able to bind to the zona pellucida of ovulated hamster oocytes (Fox and Shivers 1975), the glycoprotein has been further characterized in hamster (Leveille et al. 1987) and identified and studied in other species, including mice (Kapur and Johnson 1985, 1986), rabbits (Oliphant and Ross 1982; Oliphant et al. 1984), dogs (Saint-Dizier et al. 2014), cats (Hachen et al. 2012a), sheep (Sutton et al. 1984; 1986; Gandolfi et al. 1989), pigs (Buhi et al. 1990), cows (Malayer et al. 1988; Boice et al. 1990a, b), rhesus monkeys (Verhage et al. 1997), baboons (Fazleabas and Verhage 1986; Verhage et al. 1989,

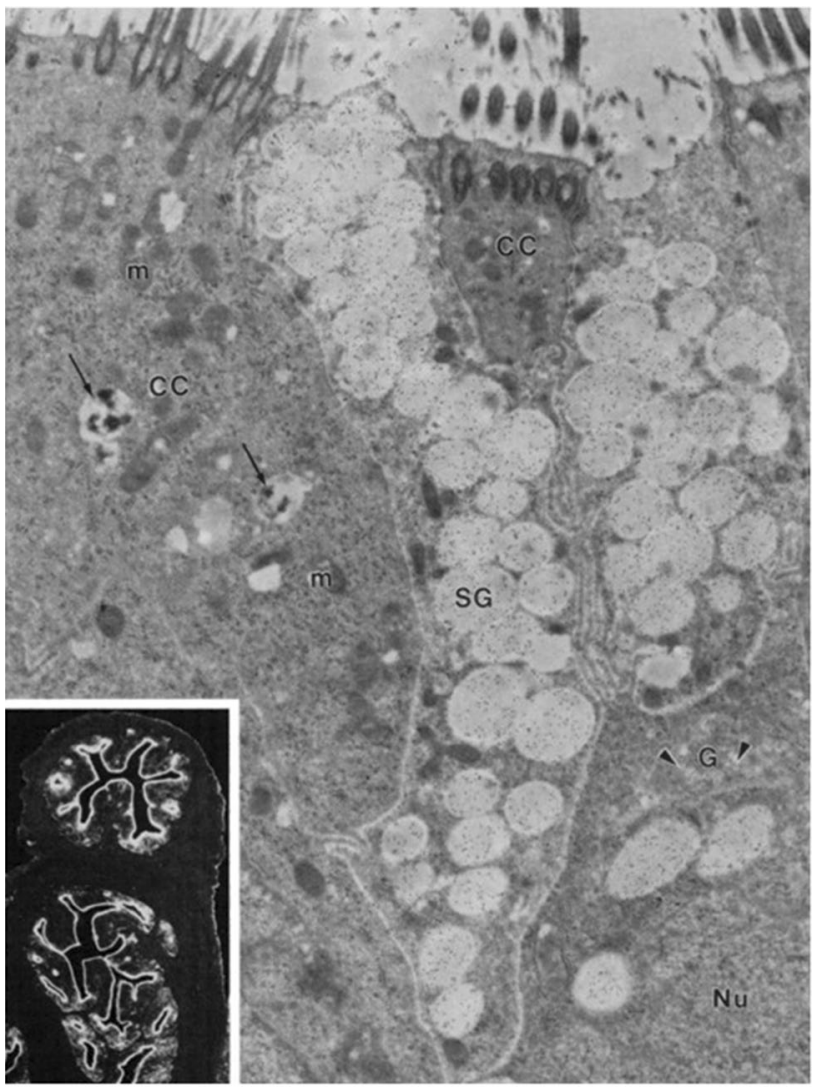

Fig. 1 Electron photomicrograph showing the hamster oviduct epithelial cells at the ultrastructural level. Labeling for OVGP1, indicated by gold particles, is dense over the secretory granules (SG) of the nonciliated, secretory cells. Gold particles are also seen over the Golgi apparatus (G) and its associated vesicles (arrowheads). Ciliated cells (CC), characterized by their apical cilia and the presence of lysosome-like bodies (arrows) in the cytoplasm, are not labeled. $\mathrm{Nu}$ nucleus, $m$ mitochondria. Magnification, 15,200×. Inset: Paraffin section of hamster oviductal tissue labeled with monoclonal antibody against hamster OVGP1. Immunostaining is limited to the epithelial cells. Magnification, 200×. (From Kan et al. 1989)

1990), and humans (Verhage et al. 1988). Except for the mouse, mammalian species examined to date showed the binding of OVGP1 to the zona pellucida of post-ovulatory oocytes of the same species. A proteomic study done in sheep indicated that OVGP1 is the most abundant protein found in the oviductal fluid with a 1.7-5.5 fold increase during the estrus stage compared with the diestrus stage (Soleilhavoup et al. 2016).

Accumulating evidence indicates that mammalian OVGP1 exerts positive effects during early events of fertilization and early embryo development. However, the molecular mechanisms that regulate the physiological function of OVGP1 in these events are not fully understood. This is mainly due to the fact that it is costly and technical difficult to obtain large quantities of oviductal fluid for subsequent purification of OVGP1 in rodents and farm animals. 
In humans, it is ethically impossible to obtain adequate amounts of oviductal fluid for purification of OVGP1 for functional and mechanistic studies. In our laboratory, we successfully produced recombinant hamster OVGP1 (rHamOVGP1) using recombinant DNA technology to study the role of OVGP1 in early events of fertilization including sperm capacitation, acrosome reaction, and sperm binding to zona pellucida (ZP) in vitro (Yang et al. 2015). Subsequently, we produced recombinant human OVGP1 (rHuOVGP1) to examine the role of human OVGP1 in enhancing human sperm functions (Yang et al. 2012; Zhao et al. 2016; Zhao and Kan 2019). Details of the identification and functional properties of various OVGP1s identified and the production of recombinant OVGP1s are described below.

\section{Molecular characterization of OVGP1}

OVGP1 identified earlier in humans (Arias et al. 1994), baboons (Donnelly et al. 1991), rhesus monkeys (Verhage et al. 1997), hamsters (Suzuki et al. 1995), mice (Sendai et al. 1995), cows (Sendai et al. 1994), pigs (Buhi et al. 1996), and sheep (Desouza and Murray 1995) was found to be very conserved among species (Buhi 2002). Subsequently, OVGP1 cDNA sequence was also determined in rabbits (Yong et al. 2002) goats (Pradeep et al. 2011), and cats (Hachen et al. 2012a). Sequence analysis indicated that many of these OVGP1s have a high degree of identity $(77-84 \%)$ and similarity $(86-90 \%)$ in the $\mathrm{N}$-terminal region of the protein core and a low degree of identity (37-63\%) and similarity (50-75\%) in the C-terminal region (Buhi 2002). The mature and fully glycosylated OVGP1s vary in molecular weight (90-95 kDa in domestic animals; $110-150 \mathrm{kDa}$ in primates; $160-350 \mathrm{kDa}$ in rodents). However, the size of the protein core of several species studied to date has been found to be similar with a molecular weight of approximately $70 \mathrm{kDa}$. The variability in molecular weight is attributed to differences in glycosylation patterns (Roux et al. 1997; Verhage et al. 1997). For example, whereas the protein core of hamster OVGP1 has a molecular weight of $71 \mathrm{kDa}$, OVGP1 purified from hamster oviductal secretion is a mucin-type glycoprotein with a molecular weight of 160-350 kDa (Robitaille et al. 1988; St-Jacques and Bleau 1988; Paquette et al. 1995). The protein core of human OVGP1 is $75 \mathrm{kDa}$, whereas the secreted glycosylated form is about $110-130 \mathrm{kDa}$ (O'Day-Bowman et al. 1995).

The protein sequence alignment of OVGP1 in human, hamster, mouse, monkey, baboon, cow, goat, pig, and sheep OVGP1 is shown in Fig. 2. In silico motif scanning of OVGP1 protein revealed a domain that resembles the glycoside hydrolase 18 (GH18) family of chitinases in the N-terminal region (Malette et al. 1995b). However, the catalytic domain of OVGP1 lacks an essential glutamic acid residue that donates a proton for the hydrolysis reaction, making OVGP1 an inactive chitinase (Huang et al. 2012). Hydrophobic cluster analysis indicated that amino acids 386-525 in pig OVGP1 correspond to a C-terminal chitin-binding domain (Buhi et al. 1996). Exon arrangement analysis also revealed the chitin-binding domain in the $\mathrm{C}$-terminal region of human and mouse OVGP1 (Huang et al. 2012). Due to the divergence in the protein sequence of the $\mathrm{C}$-terminal domain of OVGP1, this region is likely to constitute both a binding domain and a species-specific recognition domain (Buhi 2002). Studies aiming to decipher the functional domains in OVGP1 may give a better understanding of the molecular mechanism of OVGP1.

The presence of mucin-type variable number tandemrepeat (VNTR) in the C-terminal region of OVGP1 also classifies OVGP1 as a member of the mucin family (Lapensée et al. 1997). The C-terminal region of hamster OVGP1 contains six VNTR sequences with 15 amino acids in each repeat (Paquette et al. 1995), while a similar region in the mouse OVGP1 contains 21 repeat sequences, each composed of seven amino acids (Sendai et al. 1995). In humans, baboons, and rhesus monkeys, the C-terminal region of OVGP1 contains only four tandem repeats, whereas cattle, sheep, and pigs have incomplete or no tandem-repeat sequences in the C-terminal region (Buhi 2002). Considering that these VNTR regions are usually heavily $O$-glycosylated, hamster and mouse OVGP1 that have more VNTR tandem repeats may be more closely related to mucins than their counterparts in other species. In addition to $O$-linked glycosylation sites, $N$-glycosylation sites also exist in the carboxy-terminal region. For example, human OVGP has four potential $\mathrm{N}$-linked glycosylation sites near the $\mathrm{C}$ terminus (Malette et al. 1995b). Unlike the other classical members of the mucin family, OVGP1 is a secreted non-gelforming unclassified mucin, suggesting different functional roles of this glycoprotein.

Glycosylation plays a critical role in the biological activity of OVGP1. The glycans of OVGP1 appear to be essential for maintaining the hydrophilicity of the protein in the extracellular environment, as complete deglycosylation of OVGP1 resulted in an insoluble protein (Satoh et al. 1995). Removal of sialic acid or $N$-linked glycans from bovine OVGP1 significantly reduced the ability of bovine OVGP1 to maintain sperm viability (Satoh et al. 1995). Furthermore, the addition of human OVGP1 inhibited hamster sperm binding to hamster oocytes, while the binding of hamster sperm to homologous oocytes was increased in the presence of hamster OVGP1 (Schmidt et al. 1997). Similarly, baboon OVGP1 inhibited the binding of human sperm to human zona pellucida, whereas human OVGP1 enhanced it as baboon OVGP1 shares 95\% sequence similarity with human (O'Day-Bowman et al. 1996). Differences in tandem repeats, the presence and 
Fig. 2 Chart showing the multiple protein sequence alignment of OVGP1 in nine different mammalian species. The top horizontal schematic shows two main regions of the OVGP1 with the N-terminal conserved glycosyl hydrolase family 18 (GH18 or chitinase) domain and C-terminal variable glycosylation region. The main schematic below shows the alignment of OVGP1 amino acid sequences of human (Homo sapiens, accession number: AAI36407.1), hamster (Mesocricetus auratus, NP 001268266.1), mouse (Mus musculus, AAI37996.1), monkey (Macaca mulatta, NP_001036252), baboon (Papio anubis, NP_001106087), cow (Bos taurus, NP_001073685), goat (Capra hircus, ABF20534), pig (Sus scrofa, NP_999235), and sheep (Ovis aries, NP_001009779) using constraint-based multiple alignment tool. The red-colored sequences are identical sequences, and the blue-colored sequences are less conserved sequences. Gray color indicates the columns that contain gaps. Where less than $50 \%$ of the sequences contain gaps, they are shown in gray uppercase and, where greater than $50 \%$ contain gaps, in gray lowercase. The black box indicates where the predicted enzymatic sites of chitinase locate on the OVGP1. Glu and Asp residues essential for the glycohydrolytic activity of the chitinase are marked by an asterisk $(*)$
Homo sapiens 1 cetus auratus 1 Mus musculus 1 acaca mulatta Bos taurus 1 Capra hircus 1 Sus scrofa 1 Ovis aries 1

Homo sapiens 8 Mesocricetus auratus Mus musculus 81 Macaca mulatta 81 Papio anubis 81 Bos taurus 21 Sus scrofa 81 ovis aries 81

Homo sapiens 161 esocricetus auretus 161 Mus musculus 161 Macaca mulatta 161 Papio anubis 161 Bos taurus 101 Capra hircus 161 \begin{tabular}{l} 
Sus scrofa 161 \\
Ovis aries \\
\hline 61
\end{tabular} Homo sapiens 241 Mesocricetus auratus 241 Mus musculus 241 Macaca mulatta 241 Papio anubis 241 Bos taurus 181 $\begin{aligned} \text { Capra hircus } & 241 \\ \text { Sus scrofa } & 241\end{aligned}$ $\begin{array}{ll}\text { Sus scrofa } & 241 \\ \text { ovis aries } & 241\end{array}$

Homo sapiens 321 Mesocricetus auratus 321 Mus musculus 321 $\begin{aligned} & \text { Mus musculus } 321 \\ & \text { Macaca mulatta } 321\end{aligned}$ Papio anubis 321

Bos taurus 261 Capra hircus 321 ovis aries 321

Homo sapiens 401 Mesocricetus aurat Mus musculus 401 Macaca mulatta 401 Papio anubis 401 Bos taurus 341 Capra hircus 401 Sus scrofa 401 ovis aries 401

Homo sapiens 472 Mesocricetus auratus 481 Mus musculus 481 Macaca mulatta 472 Papio anubis 472 Bos taurus 412 Capra hircus 472 Sus scrofa 472 Homo sapiens 501 Mesocricetus auratus 539 Mus musculus 560 Macaca mulatta 512 Papio anubis 512 Bos taurus 448 Capra hircus 508 ovis aries 508

Homo sapiens 540 cetus auratus 589 Mus musculus 640 Macaca mulatta
Papio anubis

Papio anubis
Bos taurus Bos taurus

Capra hircus
Sus scrofa ovis aries

Homo sapiens 6 Mesocricetus auratus Mus musculus Macaca mulatta Papio anubis Bos taurus Capra hircus Sus scrofa
Ovis aries
MWKLILWVGLVLVLKHHDGAAHKLVCYFTNWAHSRPGPASILPHDLDPFLCTHLIFAFASMNNNOIVAKDLODEKILYPE 80 MGRLIINVGLVLIMKPNDGTAYKLVCYFTNWHHSRPVPASTIPRDIDPFLCTHLIFAFASMSNNOIVANNLODEKILYPE 80 MGRLLLLAGLVLLMKHSDGTAYKLVCYFTNWAHSRPGPASIMPHDLDPFLCTHLIFAFASMSNNOIVAKNLODENVLYPE 80 MWKLLLWVGLVLVLKHHDGAAHKLVCYFTNWAHSRPGPASILPHDLDPFLCTHLIFAFASMNNNOIVAKDLODEKILYPE 80 MWKLLLWVGLVLVLKHHDGAAHKLVCYFTNWAHSRPGPASILPHDLDPFLCTHLIFAFASMNNNOIVAKDLODEKILYPE 80 MGKLLLWIGLLLMLKHHDGAAHKLVCYFTNWAF SRPSPASILPRDLDPFLCTHLVFAFASMNNNOIVPKDPLDEKILYPE 80 MGKLLLWVGLVLVLKHHNGAAHKLVCYFANWAF SRPGPASILPRDLDPFLCTHLVFAFASMNDSQIVAKDARDESIFYPE 80 MGKLLLWVGLIIMLKHHDGAAHKLVCYFTNWAF SRPGSASILPRDLDPFLCTHLVFAFASMNNNOIVPKDPLDEKILYPE 80

FNKLKERNRELKTLIS IGGWNFGTSRFTTMLSTFANREKF IASVISLLRTHDFDGLDLFFLYP ELRGSPMHDRWTFLFLI 160 FNLKERNRA KTHUVGGWNF GISRFTTMLSTLASREKF IGSVVSFLRTHGFDGLDLFFLY P ELRGSPINDRWNFLFLI 160 FNKLKERNRELKTLIS IGGWNFGTSRFTAMLSTLANREKF IDSVISFLRIHGFDGLDLFFLYP PLRGSPPHDRWNFLFLI 160 FNKLKERNRELKTLIS IGGWNF GTSRFTTMLSTFANREKF IASVISLLRIHDFDGLDLFFLYP ELRGSPMHDRWTFLFLI 160 FNKLKERNRELKTLLSIGGWNFGISRF TTMLSTFANREKF IASVISLLRTHDFDGLDFF FYP PLRGSPMHDRWTFLFLI 160 FNKLKERNRGLKTLLS IGGWNFGIVRFTTMLSTFSNRERFVSSVIALLRTHG DGLDLFFLYP IRRGSPARDRWTFVFLL 100 FNKLKERNRGLKTLLSVGGWNFGTSRFTKMLSTFSNRERFVNSVIALLRTHGFDGLDLFFLYP ELRGSPARDRWTFVFLL 160 FNQKERNEKLKTLISIGGWNF GTSRFT TMLSTFTNREKF IRSAIGLLRTHGFDGDLFFLYP ELRGSPRRDRWNFLFLI 160 FNKLKERNRGLKTLLSVGGWNFGISRFTKMLSTFSNRERFVKSVIALLRTHGFDGLDLFFLYP ELRGSPARDRWTFVFLI 160

EELIFAFRKEALLTMRPRLLLSAAVSGVPHIVQTSYDVRFLGRLIDFI NVLSYDLHGSWERFTGHNSPLFSLPEDPKSSA 240 EELOFAFEKEALITQRPRLLLSAAVSGIPYI IQTSYDVHLIGRRLDFINVLSYDLHGSWEKSTGHNSPLFSLPEDPKSSA 240 EELOFAFEREALITOHPRLLLSAAVSGIPSI IHTSYDALLIGRRLDFI IVLSYDLHGSWEKFTGHNSPLF SLPEDSKSSA 240 EELLFAFRKEALLTMRPRLLLSAAVSGVPHIVQTS YDVRFLGRLLDFI NVLSYDLHGSWEKFTGHNSPLF SLPEDPKSSA 240 EELLFAFRKEALLTMRPRLLLSAAVSGVPHIVQTSYDVRFLGRLLDFI NVLSYDLHGSWEKFTGHNSPLFSLPEDPKSSA 240 EELLQAF KNEAQLTMRPRLLLSAAVSGDPHVVQKAYEARLIGRLIDFI SVLSYDLHGSWEKVTGHNSPLF SLPGDPKSSA 180 EELIOAFKNEAQITMRPRLILSAAVSGDPHVIQKAYDARLIRRLIDFISVLSYDLHGSWEKVTGHNSPLF SLPGDPKSSA 240 ELLLAF RREA QL TMRPRLLLSAAVSADPHVIQKAYDVRLIGRLLDF INVLSYDLHGSWEKVTGHNSPLF SLSDDPKSSA 240 QRFNEALTMR RLLLLAAVSGDPHVIQKAYDARLLGRLLDFISVLSYDLHGSWENVIGHNSPLFSLPGDPKSSA 240

YAYNYWRKLGAPSEKL IMGI PTYGRTF RLIKAS KNGLQARAI GPAS PGKYTKOEGFLAYFEICSFVWGAKKHWIDYQYVP 320 FAMNYWRNLGAPADKLLMGF PAYGRTFHLLRES KNGLQAASMGPAS PGKYTKOAGFLAYYEVCSF IORAEKKHIDHQYVP 320 YAMNYWRKLGTPADKL IMGFPTYGRNF YLIKES KNGLQTASMGPAS PGKYTKOSGFLAY YEVCSFVQRAKKHWIDYQYVP 320 YAMNYWRKLGAPSEKL IMGI PTYGRTF RLIKAS KNGLQATAVGPASPGKYTKOAGFLAYFEICSFVWGAKKHWIDYOYVP 320 YAMNYWRKL GAPSEKL IMGI PTYGRTFRLIKAS KNGLQATAIGPAS PGKYTROAGFLAYFEICSFVWGAKKHWIDYOYVP 320 ZAMNYWROLGVPPEKL LMGLPTYGRTF HLIKASONELRAOAVGPAS PGKYTKOAGFLAYYYICCFVRRAKKRWINDOYVP 260 YAMSYWRQLGVPPEKLLMGLPTYGRTF HLLRASQNELGAGAVGPASPGKYTKOAGFLAYYEVCSFVQRAKKRWINDOYVP 320 WATKR

YANKGKEWVGYDNAISFS YKAWFIRREHFGGAMVWTLDMDDVRGTFCGTGPFPLVYVLNDILVRAEFSSTSLPQFWLSSA 400 YAYKGKEWVGYDDAVSF YKAMFVKKEHFGGAMVWTLDMDDVRGTFCGNGPFPLVHILNELLVRAEFNSTPLPQFWFTLP 400 YAFRGKEWLGYDDTISFS SKAMYVKREHFGGAMVWTLDMDDVRGTFCGNGPFPLVHILNELLVQTESNSTPLPOFWFTSS 400 ZANKGKEWVGYDDAISF S YKAWFIRREHF GGAMVWTLDMDDVKGTF CGTGPFPLVYVLNDILVRAEFSSTSLPQFWLSSA 400 XANKGKEWVGDDAISF SYKAWFIRREHFGGAMVWTLDMDDVRGTF CGTGPFPLVYVMNDILVRAEFSSTSLPQFWLSSA 400 YAFKGKEW WYDDATSFGYKAFFTKREHFGGAMU WLDLDFRGYFCGTGPFPLVHTLNNLLWNDEFSSTPSPKFFSTA 340 ZAFKGKEW GYDDAISFGYKAFFIKREHFGGAMUTLDLDDRGNFCGIGPFPLVHTLNNLLUNDEFSSTPSPKFWFSTA 400 עa

WNSSSTDPERLAVTTAWTTD-SKILPPGGEAGVTEIHGKCENMTITPRGTTVTP------TKETVSLGKHTVALGEKT-- 471 NSSGPGSESLPATEELTTD VVKILPPGGEAMATEVHRKYEKVTTIPNGGFVTPagttsPTTHAVALERNAMAPGAKTt 480 VNASGPGSENTALTEVLTTDEIKILPPGGEAMTTEVHRRYENMTTVPSDGSVTPggt as PRKHAVTPENNTMAAEAKTMS 480 NNSSSTEPERLAVTKAWTTD-IKILPPGGEAGVTE INGKCENMT ITPRVTIVTP-------TKETVSLGKHTVALGEKT-- 471 NNSSTDPERLAVTKAWTTD-IKILPPGGEAGVTE IHGKCENMT ITPRVTIVTP-------TKETVSLGKHTVALGEKT-- 471 NNSSRIGPEMP TMTRDLTTG-LGILPPGGEAVATETHRKSETMTITPKGEIATP------TRTPLSFGRRTAAPEGKT-- 411 WNSRIGPEMPTMTRDLTTG-LGILPLGGEAMATETHRKSATMTTTPRGETATP------TRTPLSFGRRTAAPEGKT-- 471 VISSR

STE IdffsktttgvsktttgisKTTTGVSKTTTG-ISKTITGVSKTTTGVSKatagisktipeiskatagvsktitGVSKTT 559 ------------EITGATTMT SVGHOSMTPGEKALTPVGHOSOL -

---SVTTGQKTLTSVGYQSVT-PGEKTL-----------TPVGHQSVTPV------------------------SHQS 539 GNOSVTPGGETVTIVGNKSVTPVGETV---------TIVGNKSVTPG--------------gqttatVGSOS 588 GVSKITTGVSKTTTGISKTTTgISQTITgisktt tdiskTTTGISKTTPGiskttpgmtvivqtqaneaet tatmDHOS 639 VHOSVTTGQKTLISVGYHSVTPPGEKTL----------TPVDHPSVTPV---------------------SHOS 555 GHOSVTTGQKTLISVGYHSVT-PGERTL----------TPVGHPSVTPV---------------------SHQS 554

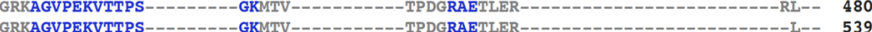

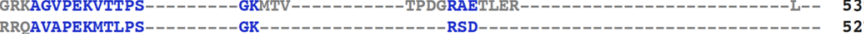
GRKAGVPEKVTIPS---------GKMTV-----------TPDGRAETLER---------------------------L-- 539 VSPGGTTMTPVHFOTETLRONTVAPRRKAVAREKVTVPSRISVTPEGOTMPLRGENLTSEVGTHPRMGn $1 \mathrm{gl}$ lqmoaen 619 VTPPGMDTTLVYLQTMTILSEKGTS-SKKAVVLEKVTVPPREISVMPNEONTALNRENLIAEVESYSODG---------- 656 VTPTGMDTTLFYLKTMTPSEKETS-RKKTMVLEKATVSPREMSATPNGOSKTLKWASLITEVETYSODG----------- 707 SSPGMTMTPVHFOTETLRONTMAPRRKAVAREKVTVPSRISVTPEGOTVPLRGEYLTSETGTHPOGG----------- 624 VSPGGMTTPVHFOTETLRONTMAPRRKAVAHEKVTVPSRKISVTPEGOTVPLRGEYLTSETGTHPODG-

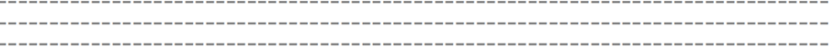

mmlssspviqlpeqtplafdnrfvpiygnhssvnsvtpqtsplslkkeipensavdeea 678

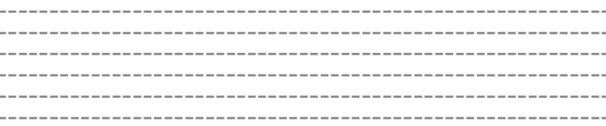


distribution of $\mathrm{N}$ - and $\mathrm{O}$-linked carbohydrate chains, the diversity of side chains, and the length of the C-terminal region may confer species specificity, mediate specific recognition events, and regulate the biological activity of OVGP1.

The expression and secretion of OVGP1 in the oviductal epithelium are differentially regulated during the menstrual cycle or estrous cycle in mammals. An incomplete estrogen-responsive element (iERE) (5'-GGTCANNNTGACT-3') was found at the position 150-162 bp before the start codon of the promoter region of human OVGP1 (HuOVGP1) gene (Agarwal et al. 2002). DNA sequence analysis of the human OVGP1 putative promoter revealed little homology with its hamster and mouse OVGP1 gene counterparts. However, the same iERE site was found in the promoter region of OVGP1 in hamsters and mice. The iERE sequence of HuOVGP1 is capable of binding to estrogen receptor ER $\beta$ but not ER $\alpha$. Evidence of estrogen-regulated OVGP1 expression was revealed in several species, including human (Verhage et al. 1988; Arias et al. 1994; O'Day-Bowman et al. 1995; Lok et al. 2002), baboon (Verhage et al. 1990; Arias et al. 1994; Jaffe et al. 1996), sheep (Sutton et al. 1984; Buhi et al. 1991), cow (Malayer et al. 1988; Boice et al. 1990a, b), pig (Buhi et al. 1990, 1996), and hamster (McBride et al. 2004a). In species with long ovulatory cycles, the maximum mRNA and protein expression levels of OVGP1 have been found during the late follicular phase of the menstrual cycle in humans (Arias et al. 1994; O'Day-Bowman et al. 1995; Lok et al. 2002) or during the first two days of the estrous cycle in pigs (Buhi et al. 1996). OVGP1 mRNA and protein expression levels are very low or absent during the luteal phase and diestrus stage (Buhi et al. 1991, 1996; Arias et al. 1994; O'Day-Bowman et al. 1995; Verhage et al. 1998; Lok et al. 2002). Hormone replacement with estrogen after ovariectomy can restore the levels of OVGP1 mRNA and protein expression. Conversely, treatment with progesterone suppresses both mRNA and protein expression levels of OVGP1 (Buhi 2002). In hamster, the levels of OVGP1 mRNA expression are relatively the same throughout the estrous cycle (Komiya et al. 1996); however, a cyclic variation in glycosylated OVGP1 concentrations in the hamster oviduct epithelium has been found, with the highest level at the estrus stage and the lowest at diestrus (McBride et al. 2004a). A corresponding increase in glycosyltransferase activity was also found in the hamster oviduct at the time of ovulation, suggesting that glycosylation of OVGP1 may be necessary for its full functions during fertilization (McBride et al. 2004a). Based on studies carried out in various species, it appears that the protein expression of OVGP1 is under the influence of estrogen, whereas the mode of regulation and post-translational modification of OVGP1 can be different among species.

\section{Localization and biological functions of mammalian OVGP1}

The concurrence of peri-ovulatory phase and high levels of OVGP1 expression suggests that this glycoprotein may play a role during early events of fertilization. The biological functions of OVGP1 during early events of fertilization that have been proposed to date are summarized in Fig. 3 and described in detail in the following sections. Briefly, in vitro studies carried out in various mammalian species have shown that native OVGP1 can bind to sperm and oocytes and exert positive effects on both sperm and oocytes, including sperm capacitation, sperm motility and viability, sperm-egg binding, penetration rate and fertilization rate, decrease in polyspermy, embryo quality, and early embryo development.

\section{Localization of OVGP1 in the oviductal epithelium}

OVGP1 is synthesized and secreted by secretory cells in the oviductal epithelium (St-Jacques and Bleau 1988; MainesBandiera et al. 2010; Saint-Dizier et al. 2014). Northern blot analysis showed that mRNA transcripts for OVGP1 are found exclusively in the oviduct and not in any other tissues in hamsters (Suzuki et al. 1995). The protein expression of OVGP1 gradually increases as the animal becomes sexually mature (Malette et al. 1995a). At the ultrastructural level, OVGP1 was found to be localized within the secretory granules and Golgi saccules in nonciliated secretory cells but not ciliated cells of the oviductal epithelium in hamster (Fig. 1) (Kan et al. 1989; McBride et al. 2004a). Results obtained with human oviducts using immunohistochemistry, Western blotting, and reverse-transcription polymerase chain reaction (RT-PCR) showed that maximal production of OVGP1 occurs around the time of ovulation (O'Day-Bowman et al. 1995; Lok et al. 2002). In hamster, an increased level of expression of mature and fully glycosylated OVGP1 occurs during the peri-ovulatory phase as demonstrated by quantitative immunocytochemistry (Figs. 4 and 5), suggesting an important role for OVGP1 in the fertilization process.

\section{Binding of OVGP1 to sperm}

OVGP1 has been shown to bind to sperm and has positive effects on sperm capacitation, viability, motility, and acrosome reaction (King et al. 1994; Abe et al. 1995; Killian 


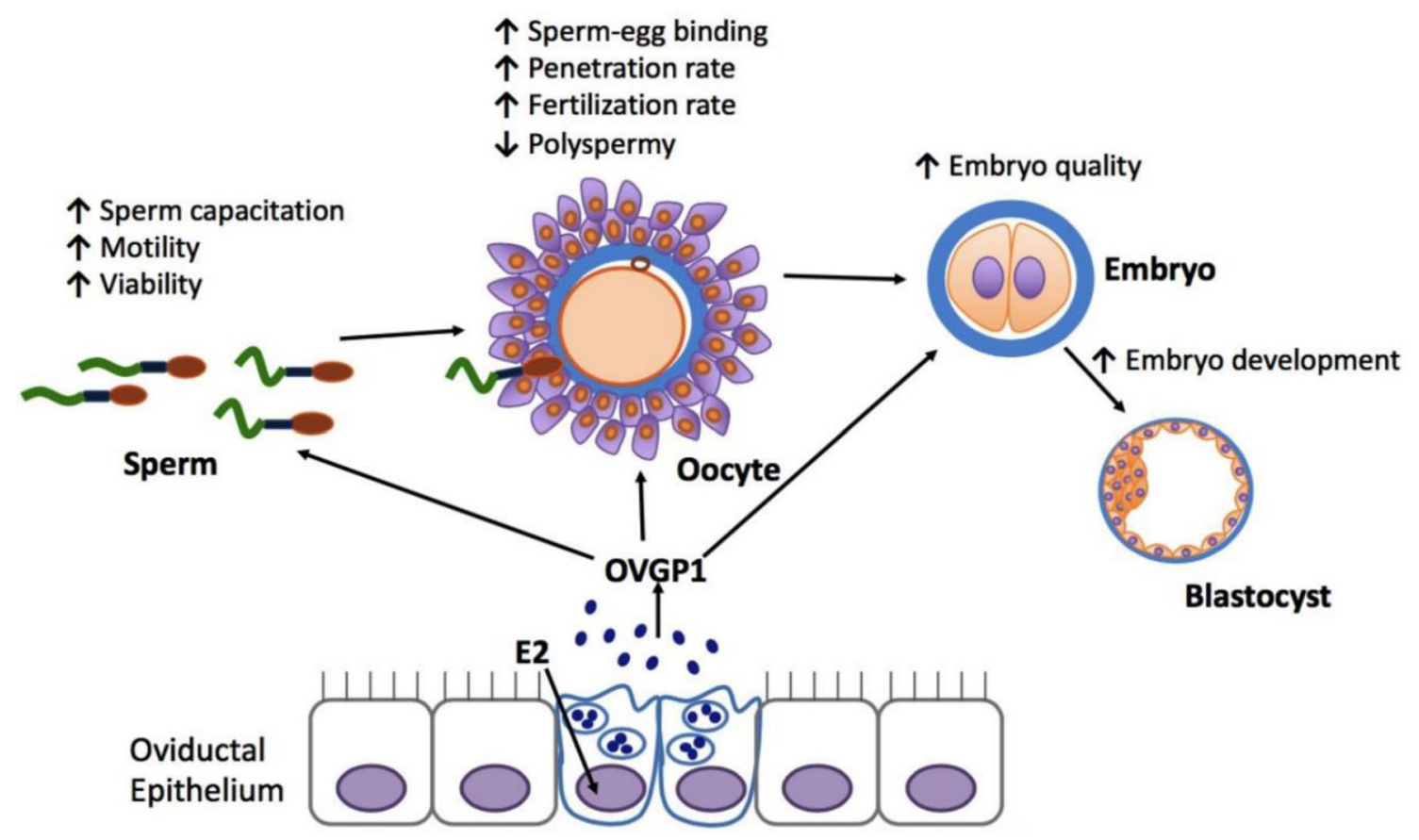

Fig. 3 Schematic diagram summarizing the proposed biological functions of OVGP1. The synthesis and secretion of OVGP1 are influenced by the level of estrogen (E2). In vitro studies from various mammalian species have shown that native OVGP1 can bind to sperm and oocytes and enhance sperm capacitation and increase

2004). Binding of partially purified hamster OVGP1 to the head region of homologous sperm has been reported, and the pattern of binding showed regional and temporal modifications during sperm capacitation (Boatman and Magnoni 1995). In noncapacitated sperm, OVGP1 binds to the acrosomal region of sperm head. After capacitation, OVGP1 was found to be over the equatorial segment and post-acrosomal region (Boatman and Magnoni 1995). The increase in binding of hamster OVGP1 to the acrosomal and post-acrosomal regions of homologous sperm during capacitation has been shown by immunolabeling using the surface-replica technique (Fig. 6). As OVGP1 is the major glycoprotein secreted by the oviductal epithelium, binding of OVGP1 to the head region of sperm is thought to be involved in sperm-oviduct interaction. Localization of OVGP1 to different membrane domains of mammalian sperm varies among species. In bovine, OVGP1 binds to the posterior region of the sperm head and the mid-piece of sperm tail (Abe et al. 1995). In humans, an earlier study detected the binding of oviductspecific glycoprotein over the surface of the head region (Lippes and Wagh 1989). As described below, the use of recombinant human OVGP1 revealed its localization to specific membrane domains of human sperm.

The binding of OVGP1 to sperm appears to exert positive effects on sperm functions. Incubating bovine spermatozoa with purified OVGP1 in conditioned medium sperm motility and viability. Native OVGP1 can also enhance spermegg binding, increase sperm penetration rate and fertilization rate, decrease polyspermy, enhance embryo quality, and increase the number of embryos that develop to blastocysts

can enhance sperm capacitation, increase the potential of sperm to undergo acrosome reaction, enhance the ability of sperm to fertilize bovine oocytes (King et al. 1994; Satoh et al. 1995), and increase sperm motility and viability in a dose-dependent manner (Abe et al. 1995). Partially purified porcine OVGP1 added to the incubating medium at low concentrations was able to increase viability of porcine sperm (McCauley et al. 2003). Purified hamster OVGP1 from the estrus stage was shown to increase the levels of tyrosine phosphorylation of sperm proteins, a biochemical hallmark of sperm capacitation, in a time-dependent manner (Saccary et al., 2013b). Taken together, the above findings obtained from in vitro functional studies of OVGP1 indicate the beneficial effects of the presence of OVGP1 in the capacitating medium in terms of sperm functions, suggesting that supplementing the incubating medium with OVGP1 could enhance the fertilizing competence of sperm.

\section{Binding of OVGP1 to oocytes}

Localization of OVGP1 to the zona pellucida of oviductal oocytes was one of the characteristic features of this glycoprotein (Araki et al. 1987, O'Day-Bowman et al. 1996; Coy et al. 2008). OVGP1 is absent in the ovarian follicles in the ovary and is added to the zona pellucida of post-ovulatory 
Fig. 4 Electron photomicrographs of ultra-thin Lowicryl sections of hamster oviducts obtained from different stages of the estrous cycle and immunolabeled for hamster OVGP1 by use of the protein A-gold technique. At diestrus $1(\mathbf{1})$, the secretory granules (SG) of a nonciliated secretory cell are weakly labeled by gold particles. At proestrus (2), the labeling density of gold particles in the secretory granules (SG) is seen to be relatively higher. The highest concentration of gold particles is found in the secretory granules (SG) of the secretory cells at estrus (3). Magnification, 19,000×. (From Roux and Kan 1995)
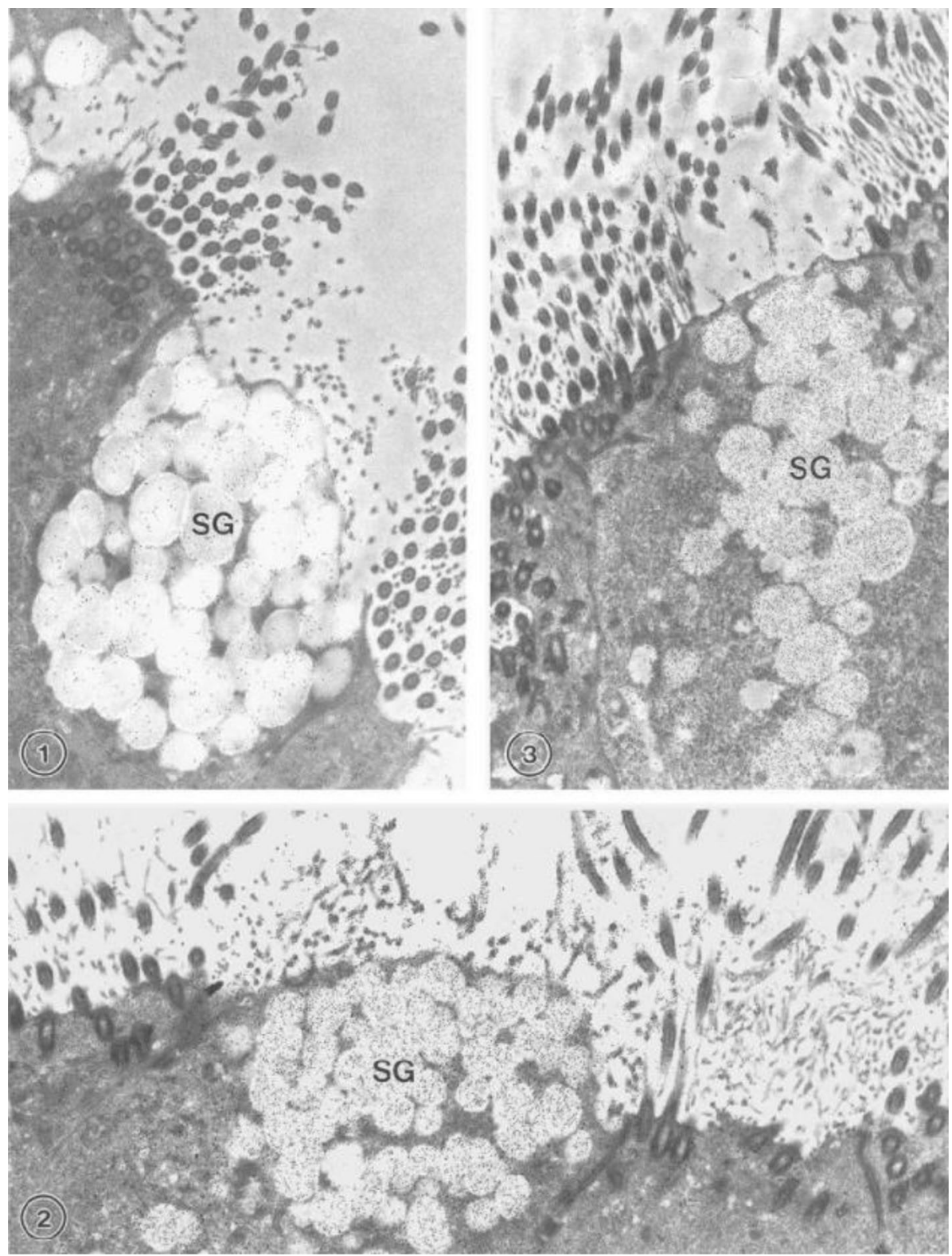

oocytes during oviductal transit (Araki et al. 1987; StJacques and Bleau 1988; Kan et al. 1989; Abe and Oikawa 1990). The glycoprotein is specifically associated with dense filamentous structures comprising the zona matrix (Kan et al. 1990; McBride et al. 2004b). Immunolocalization studies at the ultrastructural level revealed the presence of the glycoprotein on the microvilli and in the perivitelline space of fertilized hamster oocytes and in the multivesicular bodies of early embryos (Kan et al. 1990, 1993; Kan and Roux 1995; McBride et al. 2004b). Similarly, in baboons, incubating oocytes with extracted oviductal fluid or purified homologous OVGP1 also showed binding of OVGP1 to the zona pellucida (O'Day-Bowman et al. 2002).

Binding of OVGP1 to the zona pellucida appears to modify the functions of zona pellucida. Co-incubating human sperm and hemizonae in the presence of human OVGP1 and co-incubation of hamster sperm and retrieved ovarian oocytes in the presence of hamster OVGP1 enhanced sperm-zona binding and sperm-egg penetration (Boatman and Magnoni 1995; O’Day-Bowman et al. 1996). Despite the high homology between human and baboon OVGP1, addition of baboon OVGP1 in the human hemizona binding assay resulted in a decrease in binding of sperm to hemizonae, indicating the importance of species specificity in sperm-egg binding (O'Day-Bowman et al. 1996).

Treatment of bovine and porcine ovarian oocytes with homologous OVGP1 prior to incubation with the respective sperm has shown positive effects on fertilization. Bovine oocytes preincubated with homologous OVGP1 resulted in a significant increase in fertilization rates, even with a smaller 


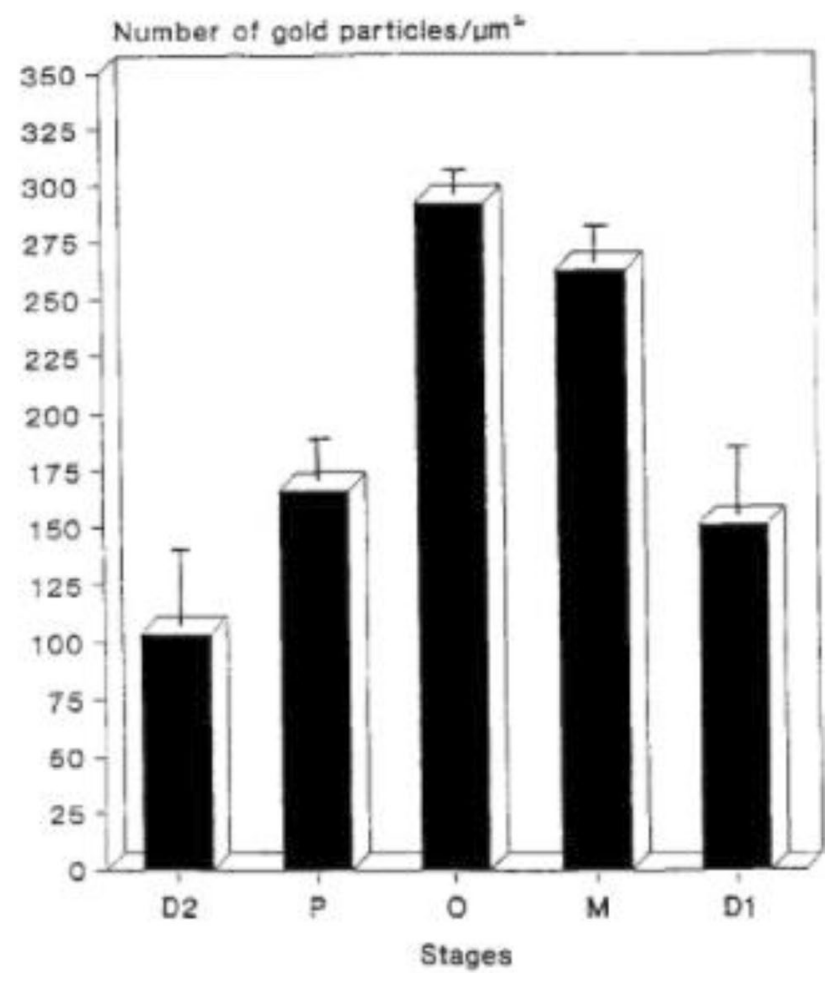

Fig. 5 Histogram showing mean labeling density of hamster OVGP1 [expressed in histogram as the number of gold particles per $\mu \mathrm{m}^{2} \pm$ standard error of the mean (SEM)] in the secretory granules of hamster oviduct obtained from five different stages of the estrous cycle. $D 2$ diestrus, $P$ proestrus, $O$ estrus, $M$ metestrus, $D 1$ diestrus 1. (From Roux and Kan 1995)

number of sperm used to fertilize the oocytes (Martus et al. 1998). In livestock, polyspermy is a common phenomenon that affects the success rate of in vitro fertilization (Suzuki et al. 2003). In pigs, polyspermy was significantly reduced when oocytes were pretreated with low concentrations of OVGP1 while high penetration and fertilization rates were maintained (McCauley et al. 2003). Similarly, in another study, porcine OVGP1 added in the IVF medium at low concentration $(<20 \mu \mathrm{g} / \mathrm{mL})$ maintained high penetration rates with a significant decrease in polyspermy (Kouba et al. 2000). On the contrary, treating porcine sperm with high concentrations of OVGP1 reduced sperm penetration and binding of sperm to oocytes. Goat OVGP1 was found to be capable of increasing the resistance of zona pellucida to pronase digestion in a dose-dependent manner; however, the presence of low concentrations of OVGP1 in the incubating medium resulted in a higher cleavage rate of the fertilized oocytes, and more embryos developed to morula and blastocyst stages (Pradeep et al. 2011). Taken together, in vitro functional studies showed that OVGP1 in various mammalian species exerts positive effects on both sperm and oocytes, albeit with varying degrees among different species.

\section{Uptake and internalization of OVGP1 by early embryos}

Uptake and internalization of OVGP1 by oocytes have been reported in the hamster and baboon, suggesting that OVGP1 may play a role in early embryo development (Kan and Roux 1995; Boice et al. 1990a, b). Following fertilization of hamster oocytes, shedding of zona pellucida as flocculent material containing OVGP1 was found in the perivitelline space of early embryos. This flocculent material was also found in coated pits, coated vesicles, multivesicular bodies, and lysosome-like structures in the blastomeres of developing embryos, indicating that OVGP1 is endocytosed and internalized by blastomeres during early embryo development (Kan and Roux 1995). Incubation of ovine spermatozoa and oocytes with OVGP1 during fertilization showed a significant increase in cleavage rate and the number of embryos developed to blastocysts (Hill et al. 1996a); however, the addition of OVGP1 to the culture medium after in vitro fertilization showed no effect on cleavage rates (Hill et al. 1996b). During in vitro fertilization in the pig in the presence of porcine OVGP1, an increase in the number of embryos that developed to the blastocyst stage was observed, although no effects on cleavage rates were noted (Kouba et al. 2000). Similarly, in sheep, while the addition of OVGP1 in the culture medium during in vitro fertilization was found to have no effects on cleavage rates, a high yield of blastocysts and a shorter time for fertilized oocytes to develop to blastocyst stage were observed (Hill et al. 1997). Therefore, results obtained from the above studies indicate that the uptake of OVGP1 by early embryos has an embryotrophic role during early embryo development.

\section{Extra-oviductal localization of OVGP1}

Although studies of synthesis and secretion of OVGP1 indicated that OVGP1 is exclusively synthesized and secreted by the oviductal epithelium (Buhi 2002; Aviles et al. 2010), OVGP1 has been detected at the apical surface of the epithelium lining the endometrium in hamsters. Upon release from the oviductal secretory cells, hamster OVGP1 gains access to the uterine lumen and binds to the microvilli of endometrial epithelial cells and becomes internalized (Martoglio and Kan 1996; Roux et al. 1997; McBride et al. 2004b). During early gestation in hamsters, immunolabeling of OVGP1 over the cell surface of the uterine epithelium was found to decrease in intensity from day 1 to day 6 (Roux et al. 1997). In mice, the intensity of immunostaining of OVGP1 expression at the uterine 


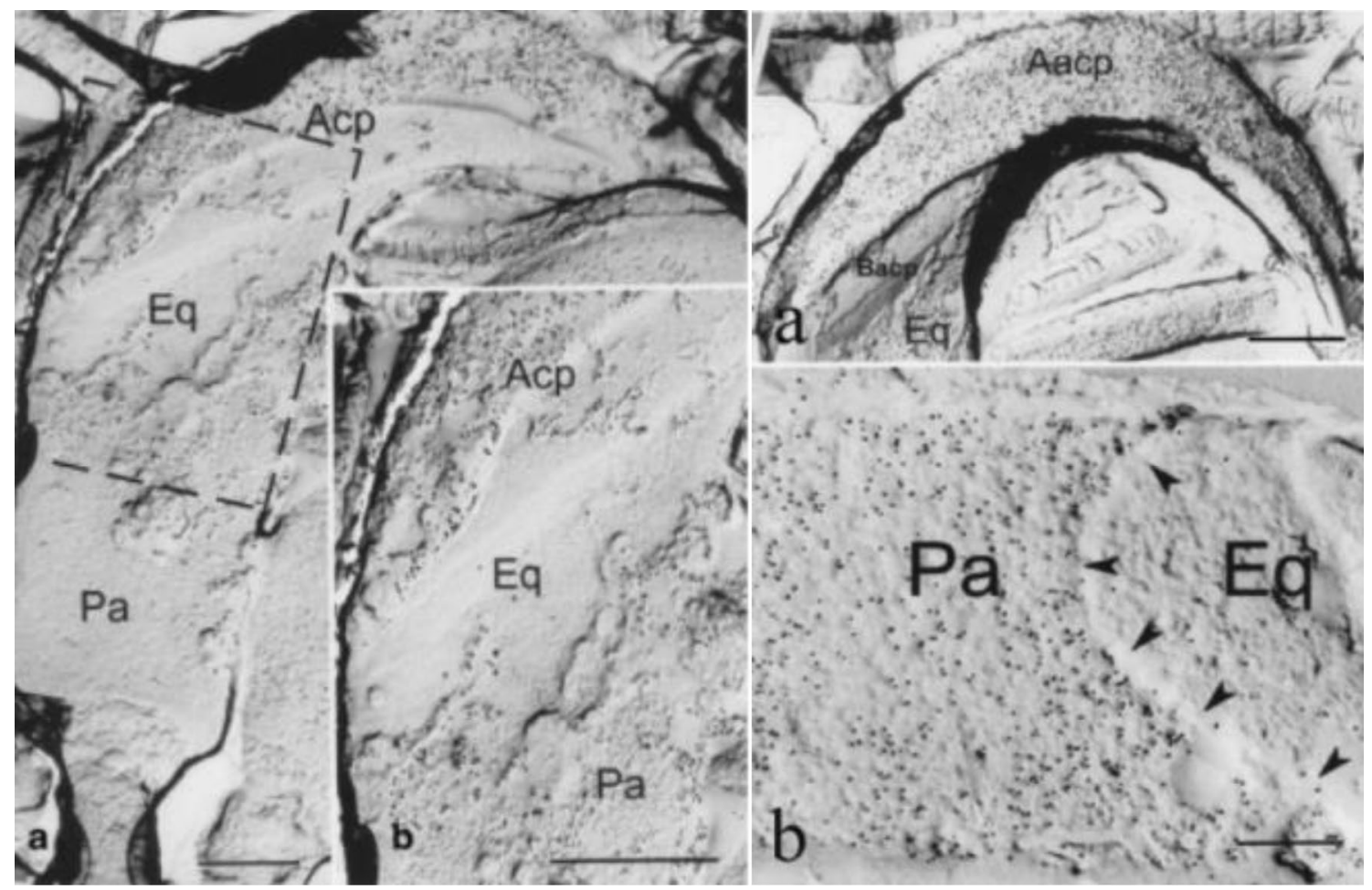

Fig. 6 Left: surface replica preparation showing the overall distribution of immunogold labeling over the sperm head of a noncapacitated hamster sperm (a). Acp acrosomal cap region, Eq equatorial segment, $\mathrm{Pa}$ post-acrosomal region. Image in (b) represents a high magnification of the region delimited by the box in (a) showing a high concentration of gold particles over the acrosomal cap region (Acp). Moderate and relatively weak labeling are also detected, respectively, over the post-acrosomal region $(\mathrm{Pa})$ and equatorial segment $(\mathrm{Eq})$. a and b: Bars, $1.0 \mu \mathrm{m}$. Right: surface replicas showing increased labeling

epithelium was found to gradually increase following conception (Laheri et al. 2018). The level of expression was most evident on day 5 after implantation and subsequently decreased. The alteration of OVGP1 protein expression levels at the uterine epithelium during implantation suggests a possible role of OVGP1 in regulating uterine receptivity. The latter authors further used OVGP1 knockdown experiments and real-time PCR to demonstrate that loss of OVGP1 in human endometrial epithelial cells altered the expression of endometrial receptivity-related genes and reduced the in vitro adhesiveness of trophoblast cells (Laheri et al. 2018). More importantly, the authors found that expression of OVGP1 mRNA was significantly lowered in the endometrium of women with recurrent implantation failure (Laheri et al. 2018). Therefore, the above findings obtained by Laheri and coworkers (2018) reinforce the notion that OVGP1 may play a role in regulating uterine receptivity during implantation and early gestation.

While studies carried out to date in various mammalian species, including humans, indicate that the synthesis and secretion of OVGP1 is oviduct-specific, it is worth by gold particles in specific regions of the sperm head after capacitation. Image in (a) shows the more intensely labeled apical acrosomal cap region (Aacp) as compared with the basal acrosomal cap region (Bacp). In (b), the post-acrosomal region $(\mathrm{Pa})$ is also strongly labeled by gold particles while only a few gold particles are seen over the equatorial segment (Eq). The post-acrosomal region and equatorial segment are separated from each other by the posterior border of the equatorial segment (arrowheads). a: Bar, $0.1 \mu \mathrm{m} ; \mathbf{b}$ : Bar, $0.5 \mu \mathrm{m}$. (From Kan and Esperanzate 2006)

mentioning that OVGP1 has been detected in the cervix of rabbit (Hendrix et al. 2001) and rhesus macaque (Slayden et al. 2018). However, the former study carried out in the rabbit utilized mainly high-performance liquid chromatography (HPLC) and Northern blot analyses, and the latter study in rhesus macaque employed an antibody against the peptide of OVGP1. Further studies are necessary to confirm both gene and protein expression of OVGP1 in the cervix and elucidate the role of OVGP1 in this segment of the uterus.

Although OVGP1 protein expression is absent in normal human ovarian tissues (McBride et al. 2004b; MainesBandiera et al. 2010; Wu et al. 2016), an increased level of OVGP1 has been detected in benign ovarian tumor fluids (Poersch et al. 2016), and also in borderline tumors, stage I and II serous carcinomas, and mucinous carcinomas (Woo et al. 2004) as compared with late-stage ovarian carcinomas. The expression profile of OVGP1 in these tumors highlights the potential of using OVGP1 as a biomarker for the detection of early stages of ovarian tumorigenesis and to improve ovarian cancer diagnosis. More work needs to be done to 
explore the use of OVGP1 as a biomarker for early detection of ovarian cancer.

To study the physiological significance of this glycoprotein, Araki and colleagues produced Ovgpl-null mice (Araki et al. 2003) and showed that Ovgpl-null mice displayed sub-fertility phenotype (i.e., smaller litter size from the Ovgp 1-null females and reduced ability of sperm to fertilize Ovgp1-null oocytes). Therefore, although OVGP1 may not be essential for in vivo reproduction in mice, its absence may result in reproductive deficits. It is also worth mentioning that, in contrast to OVGP1 identified in other mammalian species, including humans, where OVGP1 is localized to the zona pellucida, mouse OVGP1 is found in the perivitelline space of post-ovulatory oocytes instead (Kapur and Johnson 1986).

\section{Production of recombinant OVGP1}

Further studies of the functions of mammalian OVGP1 and the mechanism that regulates its functions had been hampered by the limited amounts of native OVGP1 that can be isolated and purified from rodents and farm animals. This limitation is more apparent in studies with human OVGP1 owing to ethical reasons. In the past few years, recombinant DNA technology has been used to produce recombinant OVGP1 in several mammalian species, including hamster (Yang et al. 2015), human (Zhao et al. 2016), porcine (Algarra et al. 2016), feline (Hribal et al. 2014), and buffalo (Choudhary et al. 2017) from cell cultures to generate adequate amounts of OVGP1 for functional and mechanistic studies.

\section{Recombinant hamster OVGP1 (rHamOVGP1)}

Our laboratory has successfully produced rHamOVGP1 in transfected HEK293 cells. Particularly, rHamOVGP1 can be purified using HPA-agarose affinity columns as hamster OVGP1 contains terminal $\alpha$-D-GalNAc residues (Malette and Bleau 1993). The resulting rHamOVGP1 displays a polydispersed band of 160-350 $\mathrm{kDa}$ on sodium dodecyl sulfate-polyacrylamide gel electrophoresis (SDS-PAGE) gel, with its true identity confirmed by proteomic analysis (Yang et al. 2015). The molecular mass of rHamOVGP1 corresponds to that of the purified native protein previously described (Malette and Bleau 1993). Similar to native HamOVGP1 (Boatman \& Magnoni 1995; Kan \& Esperanzate 2006; Saccary et al. 2013), rHamOVGP1 binds to homologous sperm, specifically to the head and mid-piece of hamster epididymal sperm and throughout the entire thickness of the zona pellucida of oocytes, suggesting that rHamOVGP1 may exert its effects through its binding to the head and tail regions of hamster sperm (Yang et al. 2015). Native HamOVGP1 has previously been shown to enhance sperm capacitation by increasing the level of tyrosine phosphorylation of a number of sperm proteins that are known to be involved in sperm-egg binding and sperm motility (Saccary et al. 2013). These tyrosine-phosphorylated proteins are associated with the sperm head and tail, respectively (Saccary et al. 2013). Similarly, addition of rHamOVGP1 to the capacitating medium further enhances sperm capacitation by increasing the levels of protein tyrosine phosphorylation in hamster sperm in a time-dependent manner (Yang et al. 2015). The rHamOVGP1-enhanced tyrosine-phosphorylated proteins are predominantly located in the sperm tail, suggesting a role of OVGP1 in enhancing sperm motility during capacitation. Sperm capacitation is thought to prepare sperm to undergo the subsequent acrosome reaction. Incubating hamster sperm with rHamOVGP1 in capacitation medium can significantly increase the percentage of acrosome-reacted sperm, thus increasing the fertilizing potential of sperm (Yang et al. 2015). rHamOVGP1 binds to the zona pellucida (ZP) of hamster oocytes throughout its entire thickness. Treatment of homologous sperm and/or oocytes with rHamOVGP1 prior to sperm-egg binding assay can significantly increase the number of sperm bound to the ZP of oocytes (Yang et al. 2015). The positive effect of rHamOVGP1 on sperm-oocyte binding appears to be more associated with the oocyte since the largest increase in the number of sperm bound to oocytes was noted when the sperm-egg binding essay was performed in the presence of rHamOVGP1 with pretreated oocytes and untreated sperm (Yang et al. 2015). Successful production of glycosylated recombinant hamster OVGP1 provides a valuable tool to study the biological function and the molecular mechanism of OVGP1 in mammalian fertilization.

\section{Recombinant human OVGP1 (rHuOVGP1)}

Despite the findings from animal models supporting a role for OVGP1 in fertilization and early embryo development, information concerning the biological role of human OVGP1 is lagging behind its counterpart in other mammalian species. Our laboratory utilized recombinant DNA technology to produce, for the first time, the secretory form of human OVGP1 in HEK293 cells (Zhao et al. 2016). The purified rHuOVGP1 showed a single band corresponding to the $120-150 \mathrm{kDa}$ size range of native human OVGP1, and its identity as human OVGP1 was further confirmed by mass spectrometric analysis (Zhao et al. 2016). HEK293 cells possess biosynthetic pathways of $\mathrm{N}$ - and $\mathrm{O}$-glycosylation similar to those found in immortalized human oviductal cells (Yang et al. 2012). Therefore, it is reasonable to believe that glycosylation of rHuOVGP1 in HEK293 cells is very similar to that of native HuOVGP1 in human oviductal cells. 
Fig. 7 Binding of rHuOVGP1 to human sperm during in vitro capacitation. Confocal microscopy imaging of human sperm incubated in the presence of rHuOVGP1 shows binding of the recombinant glycoprotein to membrane-intact sperm (i and ii) and $1 \%$ Triton $\mathrm{X}$-100-treated sperm (iv and $\mathbf{v}$ ) following $1 \mathrm{~h}$ (i and iv) and $4 \mathrm{~h}$ (ii and v) of capacitation. Controls show negative immunostaining when sperm were incubated in the absence of rHuOVGP1 for the membrane-intact sperm (iii) and Triton-treated sperm (vi). Scale bars, $10 \mu \mathrm{m}$. Insets: high magnifications of sperm cells revealing various immunolabeled structures. Ac acrosomal region, $E S$ equatorial segment, $M P$ mid-piece, $P A$ post-acrosomal region, $P P$ principal piece. Scale bar, $5 \mu \mathrm{m}$. (From Zhao et al. 2016)
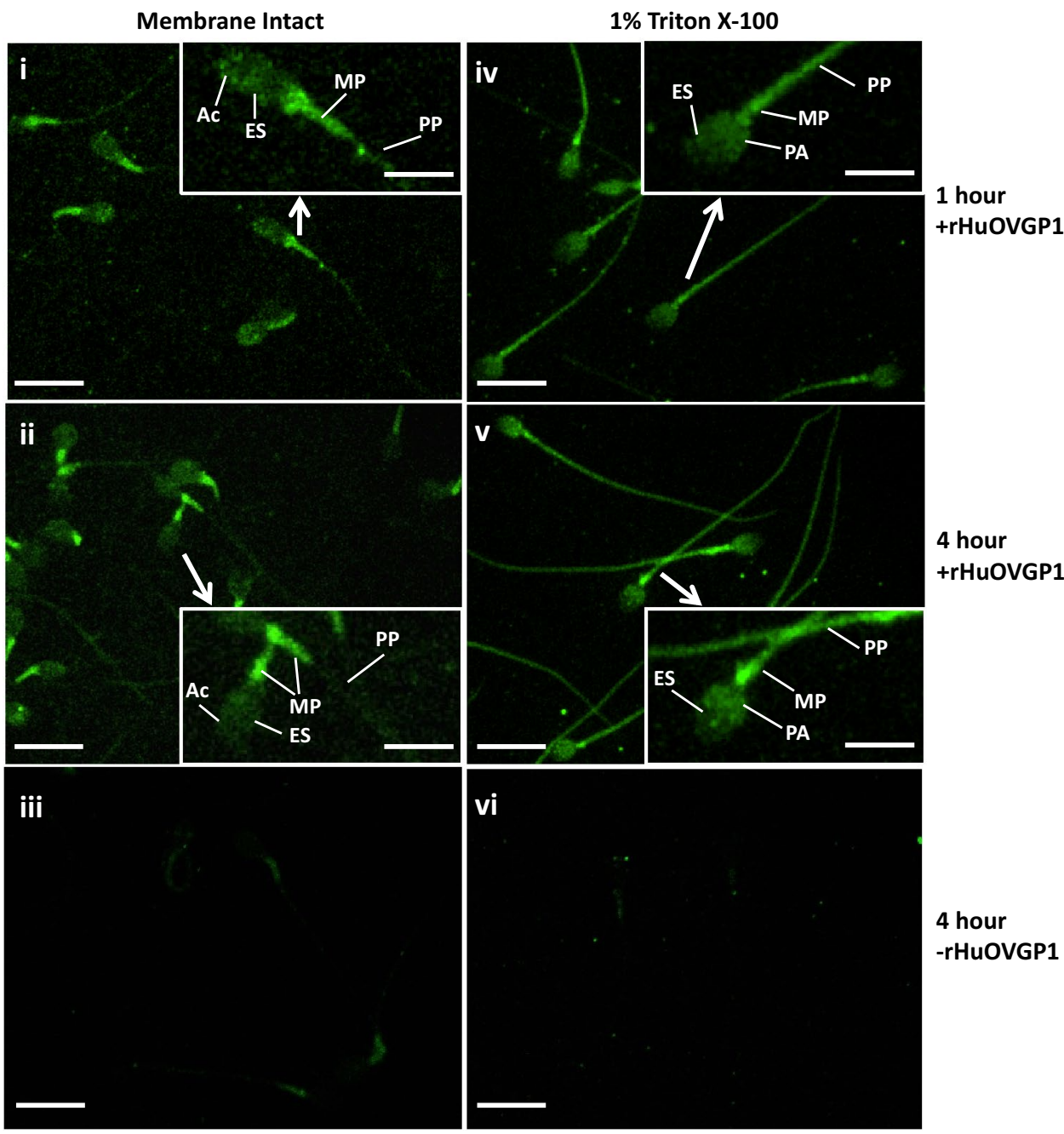

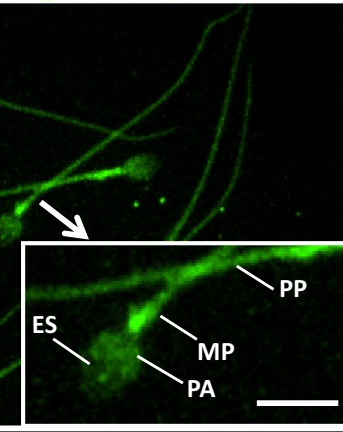

vi

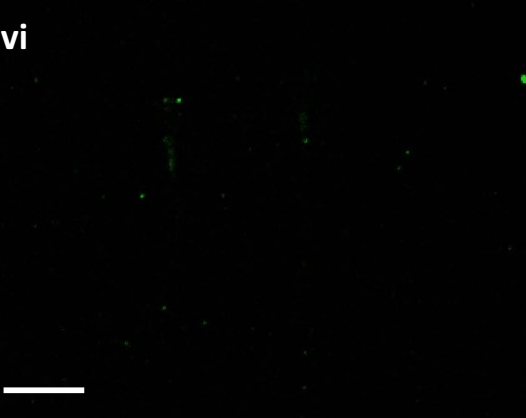

4 hour +rHuOVGP1

4 hour -rHuOVGP1
In membrane-intact sperm, rHuOVGP1 binds to the acrosomal region and equatorial segment of the sperm head, the connecting piece of the sperm neck, the mid-piece, and, to a lesser extent, the principal piece of the sperm tail (Fig. 7). Interestingly, when treated with $1 \%$ Triton X-100, a nonionic surfactant that solubilizes cell membranes and peripheral membrane-bound proteins, the binding of rHuOVGP1 displayed an altered pattern. Confocal microscopy imaging revealed relatively intense immunostaining of rHuOVGP1 over the equatorial and post-acrosomal regions in the sperm head and throughout the mid-piece and principal piece of the tail (Fig. 7). The presence of rHuOVGP1 in both the Tritonsoluble fraction and insoluble fraction (Zhao et al. 2016), along with the findings above, suggests the association of rHuOVGP1 not only with the plasma membrane of sperm but also with certain structural elements underlying the cell surfaces. Similar to the biologically active recombinant hamster OVGP1 (Yang et al. 2015), the presence of rHuOVGP1 in the incubating medium can significantly increase tyrosine phosphorylation of a subset of sperm proteins during capacitation in a time-dependent manner, and significantly increase the number of acrosomal-reacted sperm (Zhao et al. 2016). Although it is not clear whether the increase in acrosome reaction is directly linked to the increase in protein tyrosine phosphorylation under the influence of rHuOVGP1, the presence of rHuOVGP1 in the incubating medium can likely increase the fertilizing capacity of the sperm following capacitation.

Tyrosine-phosphorylated proteins are located predominantly in the fibrous sheath in the principal piece of the sperm tail (Fig. 8). The fibrous sheath has been suggested to influence the degree of flexibility, flagellar motion, and shape of the flagellar beat while functioning as a scaffold for proteins in signaling pathways involved in sperm motility and capacitation (Eddy et al. 2003). Two major components of the fibrous sheath are A-kinase anchoring proteins (AKAP) 3 and 4 (Eddy et al. 2003). Binding of protein kinase A (PKA) to tyrosine-phosphorylated AKAP3, the latter of which has been localized to the fibrous sheath of human sperm tail (Fig. 9), plays an important role in sperm motility (Luconi et al. 2005; Pereira et al. 2017). Sperm incubated with rHuOVGP1 can further potentiate the efficiency 

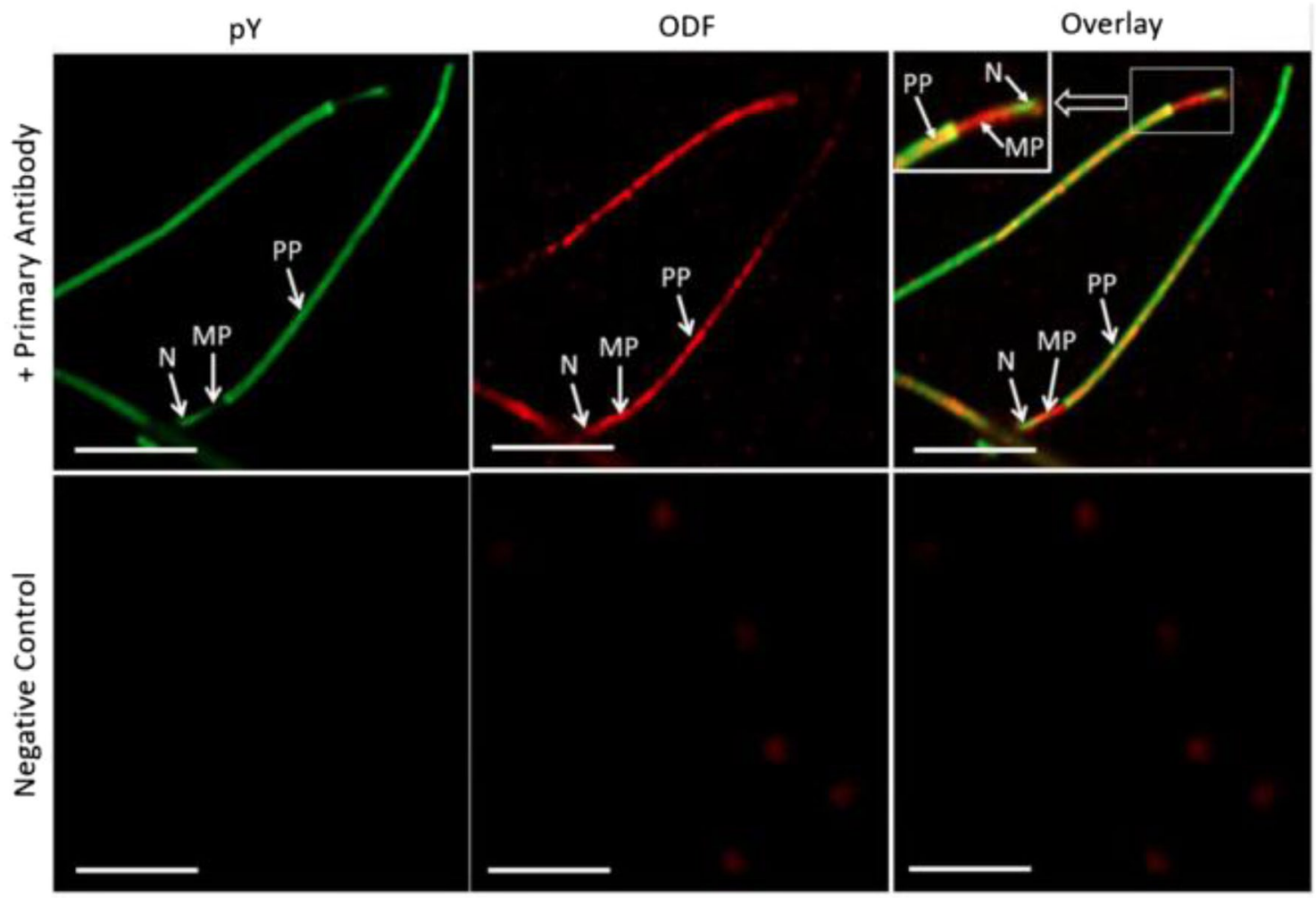

Fig. 8 Tyrosine-phosphorylated proteins are predominantly localized to the fibrous sheath of the sperm tail. Confocal fluorescent images showing the immunofluorescent labeling of tyrosine-phosphorylated sperm proteins ( $\mathrm{pY}$ ) (upper left), the outer dense fiber (ODF) protein (upper middle), the overlay image (upper right), and corresponding

of sperm to undergo acrosome reaction (Zhao et al. 2016), which is linked to increased fertilization rates. Similar to recombinant hamster OVGP1, which binds to the zona pellucida (ZP) of homologous ovarian oocytes, rHuOVGP1 also binds to the ZP of human oocytes (Fig. 10). Treatment of both hemizonae and sperm with rHuOVGP1 prior to coincubation in hemizona binding assays can increase the number of sperm bound to the $\mathrm{ZP}$ of oocytes as compared with similar conditions in the absence of rHuOVGP1 (Zhao and Kan 2019).

Accumulating evidence indicates that supplementation of rHuOVGP1 in capacitating medium in standard in vitro fertilization procedures could be beneficial for increasing the fertilization success rate. Today, a major limitation of human IVF therapy is failed sperm binding and lack of fertilization mainly due to male infertility indications. Supplementing the capacitating medium with rHuOVGP1 may be useful for treatment of male infertility with mild cases of male factor. Since studies with both rHamOVGP1 and rHuOVGP1 suggest that, in both cases, the recombinant glycoproteins enhance sperm capacitation, in part, through the increase in the level of tyrosine phosphorylation of sperm proteins, predominantly in the sperm tail, negative controls (lower panels). Insets: high magnifications of sperm cells within the framed boxes revealing various immunolabeled structures. Scale bar, $10 \mu \mathrm{m}$. $N$ neck region, $M P$ mid-piece, $P P$ principal piece. (From Zhao and Kan 2019)

that are essential for sperm motility, what remains to be determined in the future is the mechanism of OVGP1 that regulates the increase in tyrosine phosphorylation of sperm proteins during capacitation and the enhancement of sperm-egg binding. A major mechanism of sperm capacitation is the influx of calcium $\left(\mathrm{Ca}^{2+}\right)$ (Rahman et al. 2014; Jin and Yang 2017). Cumulus cells that surround the ovulated oocytes produce high concentrations of progesterone. Progesterone is known to induce $\mathrm{Ca}^{2+}$ influx and hyperactivation of sperm motility through the cation channels of sperm (Catsper) located in the sperm tail (Lishko et al. 2011; Miller et al. 2016). Our laboratory is currently investigating if HuOVGP1 can increase the intracellular $\mathrm{Ca}^{2+}$ concentrations during sperm capacitation, and, if so, studies will be carried out to examine if HuOVGP1 exerts its effect in a manner similar to that of progesterone via the Catsper channels. 
Fig. 9 AKAP3 is co-localized with $\mathrm{pY}$ proteins in the neck region and in the principal piece of the sperm tail. Confocal microscopic images of immunofluorescent labeling of $\mathrm{pY}$ proteins (a and b) and AKAP3 (c and d) on capacitated sperm with intact membrane (a, $\mathbf{c}$, and e) and Triton-DDT-extracted (b, d, and f) sperm. Bottom panel ( $\mathbf{g}$ and $\mathbf{h}$ ) shows the negative control of AKAP3 labeling. Insets: high magnifications of sperm cells within the framed boxes revealing various immunolabeled structures. Scale bar, $10 \mu \mathrm{m} . N$ neck region, $M P$ mid-piece, $P P$ principal piece, $A c$ acrosome. (From Zhao and Kan 2019)

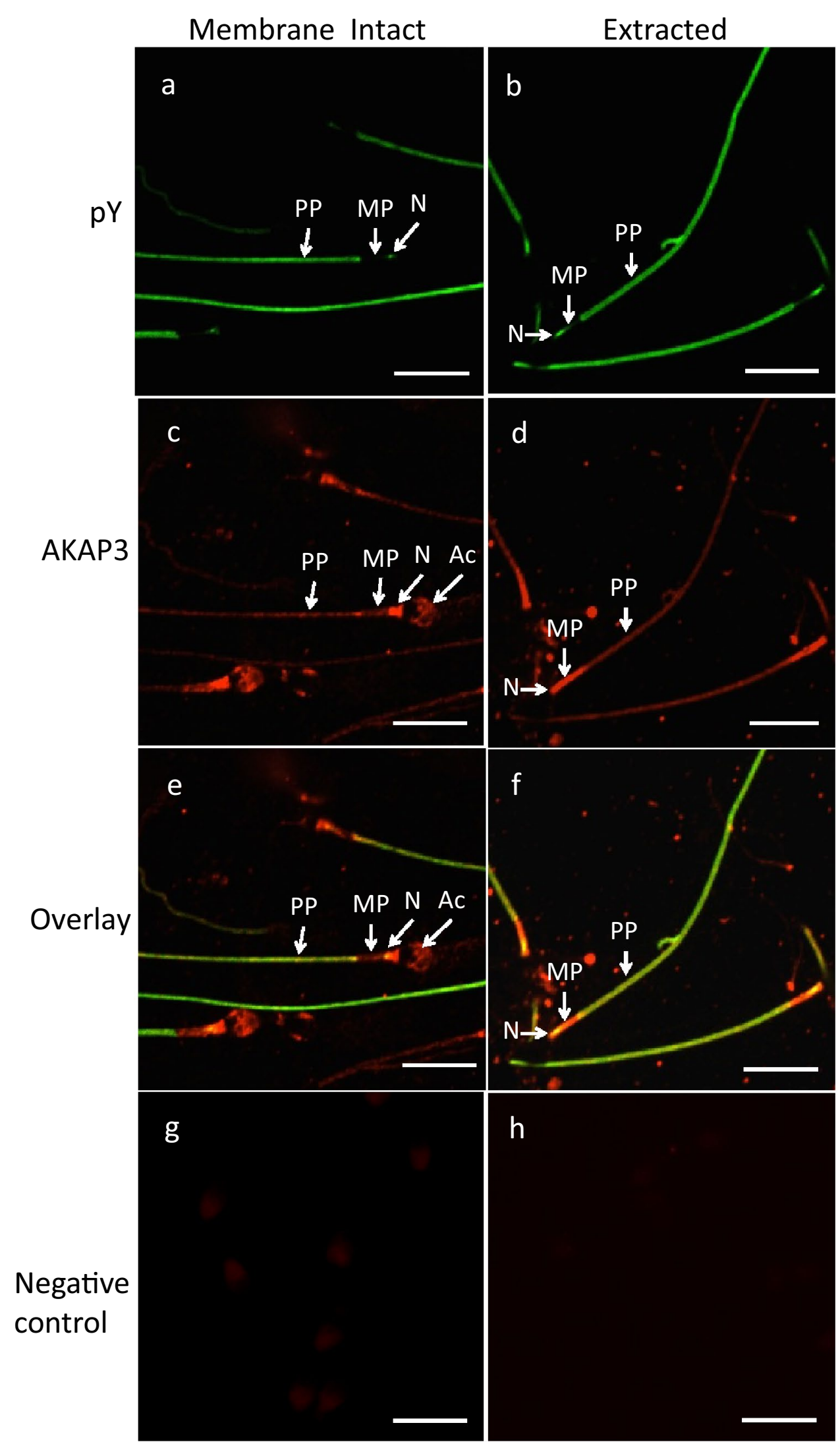


Fig. 10 rHuOVGP1 binds to the zona pellucida (ZP) of human oocytes. Microscopic images showing the immunofluorescent labeling of rHuOVGP1 in human oocytes following incubation of oocytes in the presence $(+)$ or absence $(-)$ of rHuOVGP1, with the blocking peptide specific for the OVGP1 antibody, or in the absence (-) of the primary antibody during immunolabeling, respectively. Labeling in the oocyte proper is nonspecific. Scale bar, $50 \mu \mathrm{m}$. (From Zhao and Kan 2019)

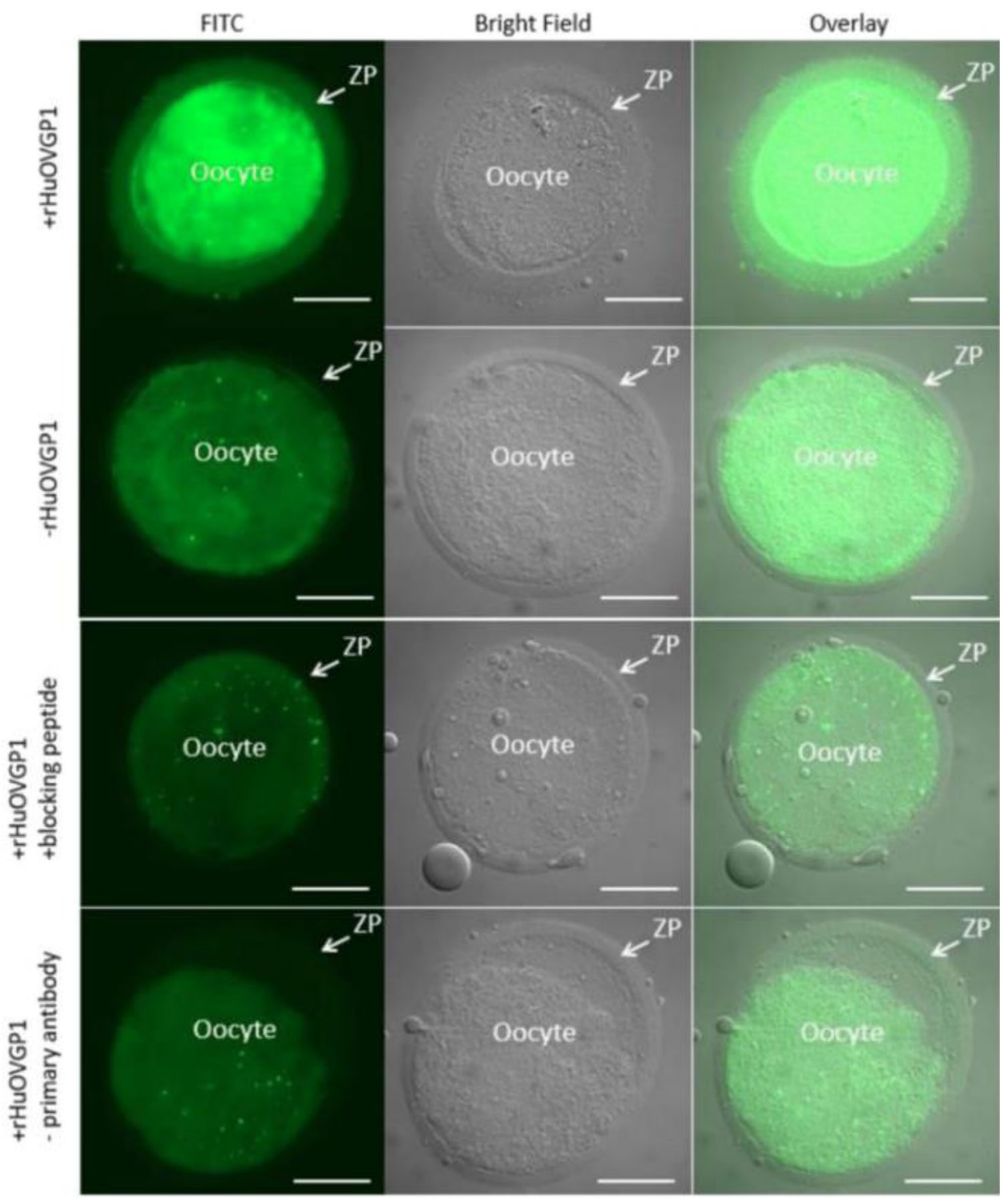

\section{Recombinant OVGP1 in other mammalian species}

In addition to the aforementioned recombinant OVGP1 of human and hamster, recombinant OVGP1 has also been produced and examined in other mammalian species. A study using recombinant porcine OVGP1 demonstrated that both full-length and truncated forms of OVGP1 were able to bind to porcine zona pellucida; however, full-length OVGP1 was able to penetrate deeper into the zona pellucida as compared with the truncated forms of recombinant porcine OVGP1 and recombinant rabbit OVGP1, and increase the efficient rate of in vitro fertilization (Algarra et al. 2016). The study also demonstrated that the $\mathrm{C}$-terminal region of recombinant porcine OVGP1 is essential for regulating several functional parameters of the ZP and its endocytosis by in vitro matured oocytes (Algarra et al. 2016). A subsequent study carried out by the same group showed that recombinant porcine OVGP1 did not affect the development rates of bovine embryos during in vitro culture, but its presence during in vitro fertilization and embryonic in vitro culture was able to produce embryos that carry relatively more embryo-specific genes (Algarra et al. 2018). However, the authors in the latter study did not observe positive effects of recombinant porcine OVGP1 on the development rates of bovine embryos. This could be due to the fact that the recombinant OVGP1 used in the latter study was not from a homologous species but from pig instead of from bull. Buffalo and feline recombinant OVGP1s have been produced, respectively, by two other research groups using a bacterial expression system (Hachen et al. 2012b; Choudhary et al. 2017). Unlike the hamster, human, and porcine recombinant OVGP1s that were produced in HEK293 cells, the buffalo and feline recombinant OVGP1s are not glycosylated. Although these two groups have shown that these unglycosylated 
recombinant OVGP1s can also benefit sperm capacitation and the fertilization process, the potential of the enhancement was thought to be less than their respective glycosylated native proteins (Hribal et al. 2014; Choudhary et al. 2017). This further implicates the glycans as important functional components of OVGP1 in mammals.

\section{Conclusion}

The present review summarizes the major findings of studies carried out in various mammalian species regarding the role of oviduct-specific glycoprotein, also known as oviductin or OVGP1, in regulating the biological functions of gametes and early embryos. Collectively, in vitro functional studies suggest that OVGP1 plays a key role in sperm capacitation, fertilization, and early embryo development. Of particular interest is the use of both recombinant hamster OVGP1 (rHamOVGP1) and recombinant human OVGP1 (rHuOVGP1) in demonstrating the association of OVGP1-enhanced tyrosine phosphorylation of sperm proteins with AKAP3, a major constituent of the fibrous sheath of the sperm tail. The successful large-scale production of recombinant mammalian OVGP1s can now pave the way for further identification and characterization of capacitation-associated and OVGP1-enhanced tyrosine phosphorylated proteins, and for further elucidation of their role in fertilization and development of early embryos. It is noteworthy to mention that, along with the use of molecular and biochemical techniques, the use of various immunohistochemical and immunocytochemical methods have contributed to our current understanding of the synthesis, secretion, and localization of OVGP1 in various mammalian species at both light and electron microscopic levels. Future studies are warranted to investigate the mechanisms that regulate the physiological functions of OVGP1. Since OVGP1 identified in various mammalian species is glycosylated, it will be of interest to examine the role of glycan derivatives of OVGP1 in early events of fertilization. It is anticipated that the use of various immunohistochemical and immunocytochemical investigative tools in conjunction with biochemical and molecular techniques will continue to be valuable investigative tools in advancing our knowledge of the importance of OVGP1 in reproductive functions.

Acknowledgements This work was supported by a research grant (PJT162451) awarded to F.W.K.K. by the Canadian Institutes of Health Research.

Open Access This article is licensed under a Creative Commons Attribution 4.0 International License, which permits use, sharing, adaptation, distribution and reproduction in any medium or format, as long as you give appropriate credit to the original author(s) and the source, provide a link to the Creative Commons licence, and indicate if changes were made. The images or other third party material in this article are included in the article's Creative Commons licence, unless indicated otherwise in a credit line to the material. If material is not included in the article's Creative Commons licence and your intended use is not permitted by statutory regulation or exceeds the permitted use, you will need to obtain permission directly from the copyright holder. To view a copy of this licence, visit http://creativecommons.org/licenses/by/4.0/.

\section{References}

Abe H, Oikawa T (1990) Ultrastructural evidence for an association between an oviductal glycoprotein and the zona pellucida of the golden hamster egg. J Exp Zool 256:210-221. https://doi.org/10. 1002/jez.1402560211

Abe H, Sendai Y, Satoh T, Hoshi H (1995) Bovine oviduct-specific glycoprotein: a potent factor for maintenance of viability and motility of bovine spermatozoa in vitro. Mol Reprod Dev 42:226-232. https://doi.org/10.1002/mrd.1080420212

Agarwal A, Yeung WSB, Lee K-F (2002) Cloning and characterization of the human oviduct-specific glycoprotein (HuOGP) gene promoter. Mol Hum Reprod 8:167-175

Algarra B, Han L, Soriano-Ubeda C et al (2016) The C-terminal region of OVGP1 remodels the zona pellucida and modifies fertility parameters. Sci Rep 6:32556. https://doi.org/10.1038/ srep32556

Algarra B, Maillo V, Avilés M et al (2018) Effects of recombinant OVGP1 protein on in vitro bovine embryo development. J Reprod Dev 64:433-443. https://doi.org/10.1262/jrd.2018-058

Araki Y, Kurata S, Oikawa T et al (1987) A monoclonal antibody reacting with the zona pellucida of the oviductal egg but not with that of the ovarian egg of the golden hamster. J Reprod Immunol 11:193-208. https://doi.org/10.1016/0165-0378(87) 90057-X

Araki Y, Nohara M, Yoshida-Komiya H et al (2003) Effect of a null mutation of the oviduct-specific glycoprotein gene on mouse fertilization. Biochem J 374:551-557. https://doi.org/10.1042/ BJ20030466

Arias EB, Verhage HG, Jaffe RC (1994) Complementary deoxyribonucleic acid cloning and molecular characterization of an estrogen-dependent human oviductal glycoprotein. Biol Reprod 51:685-694. https://doi.org/10.1095/biolreprod51.4.685

Aviles M, Gutierrez-Adan A, Coy P (2010) Oviductal secretions: will they be key factors for the future ARTs? Mol Hum Reprod 16:896-906. https://doi.org/10.1093/molehr/gaq056

Bhuvanachandra B, Madhuprakash J, Podile AR (2018) Active-site mutations improved the transglycosylation activity of Stenotrophomonas maltophilia chitinase A. Biochim Biophys Acta Proteins Proteomics 1866:407-414. https://doi.org/10.1016/J. BBAPAP.2017.12.003

Boatman DE, Magnoni GE (1995) Identification of a sperm penetration factor in the oviduct of the golden hamster. Biol Reprod 52:199-207. https://doi.org/10.1095/biolreprod52.1.199

Boice ML, Geisert RD, Blair RM, Verhage HG (1990a) Identification and characterization of bovine oviductal glycoproteins synthesized at estrus. Biol Reprod 43:457-465. https://doi.org/10.1095/ biolreprod43.3.457

Boice ML, McCarthy TJ, Mavrogianis PA et al (1990b) Localization of oviductal glycoproteins within the zona pellucida and perivitelline space of ovulated and early embryos in baboons (Papio anubis). Biol Reprod 43:340-346. https://doi.org/10.1095/biolr eprod43.2.340

Bollin F, Dechavanne V, Chevalet L (2011) Design of experiment in $\mathrm{CHO}$ and HEK transient transfection condition optimization. Protein Expr Purif 78:61-68. https://doi.org/10.1016/j.pep.2011. 02.008

Buhi W (2002) Characterization and biological roles of oviduct-specific, oestrogen-dependent glycoprotein. Reproduction 123:355362. https://doi.org/10.1530/rep.0.1230355 
Buhi WC, Alvarez IM, Sudhipong V, Dones-Smith MM (1990) Identification and characterization of de novo-synthesized porcine oviductal secretory proteins. Biol Reprod 43:929-938. https:// doi.org/10.1095/biolreprod43.6.929

Buhi WC, Bazer FW, Alvarez IM et al (1991) In vitro synthesis of oviductal proteins associated with estrus and $17 \beta$-estradiol-treated ovariectomized ewes. Endocrinology 128:3086-3095. https://doi. org/10.1210/endo-128-6-3086

Buhi WC, Alvarez IM, Choi I et al (1996) Molecular cloning and characterization of an estrogen-dependent porcine oviductal secretory glycoprotein. Biol Reprod 55:1305-1314. https://doi.org/ 10.1095/biolreprod55.6.1305

Bushnik T, Cook JL, Yuzpe AA et al (2012) Estimating the prevalence of infertility in Canada. Hum Reprod 27:738-746. https://doi.org/ 10.1093/humrep/der465

Choudhary S, Kumaresan A, Kumar M et al (2017) Effect of recombinant and native buffalo OVGP1 on sperm functions and in vitro embryo development: a comparative study. J Anim Sci Biotechnol. https://doi.org/10.1186/s40104-017-0201-5

Coy P, Canovas S, Mandejar I et al (2008) Oviduct-specific glycoprotein and heparin modulate sperm-zona pellucida interaction during fertilization and contribute to the control of polyspermy. Proc Natl Acad Sci USA 105:15809-15814. https://doi.org/10. 1073/pnas.0804422105

Desouza MM, Murray MK (1995) An estrogen-dependent secretory protein, which shares identity with chitinases, is expressed in a temporally and regionally specific manner in the sheep oviduct at the time of fertilization and embryo development. Endocrinology 136:2485-2496. https://doi.org/10.1210/endo.136.6.7750470

Donnelly KM, Fazleabas AT, Verhage HG et al (1991) Cloning of a recombinant complementary DNA to a baboon (Papio anubis) estradiol-dependent oviduct-specific glycoprotein. Mol Endocrinol 5:356-364. https://doi.org/10.1210/mend-5-3-356

Eddy EM, Toshimori K, O'Brien DA (2003) Fibrous sheath of mammalian spermatozoa. Microsc Res Tech 61:103-115. https://doi. org/10.1002/jemt. 10320

Evans MJ, Hartman SL, Wolff DW et al (1995) Rapid expression of an anti-human $\mathrm{C} 5$ chimeric Fab utilizing a vector that replicates in COS and 293 cells. J Immunol Methods 184:123-138. https:// doi.org/10.1016/0022-1759(95)00093-P

Fazleabas AT, Verhage HG (1986) The detection of oviduct-specific proteins in the baboon (Papio anubis). Biol Reprod 35:455-462. https://doi.org/10.1095/biolreprod35.2.455

Fox LL, Shivers CA (1975) Detection and localization of specific antigens in the reproductive tracts of cycling, pregnant, and ovariectomized hamsters. Fertil Steril 26:579-598. https://doi.org/10. 1016/s0015-0282(16)41178-7

Gandolfi F, Brevini TA, Richardson L et al (1989) Characterization of proteins secreted by sheep oviduct epithelial cells and their function in embryonic development. Development 106:303-312

Hachen A, Jewgenow K, Braun BC (2012a) Sequence analysis of feline oviductin and its expression $\mathrm{n}$ during the estrous cycle in the domestic cat (Felis catus). Theriogenology 77:539-549. https:// doi.org/10.1016/j.theriogenology.2011.08.029

Hachen A, Jewgenow K, Krause E, Braun BC (2012b) Recombinant feline oviductin-a powerful tool for functional IVF studies in the domestic cat. Reprod Domest Anim 47:88-92. https://doi. org/10.1111/rda.12030

Hendrix E, Hewetson A, Mansharamani M, Chilton BS (2001) Oviductin (Muc9) is expressed in rabbit endocervix. Endocrinology 142:2151. https://doi.org/10.1210/endo.142.5.8285

Hill JL, Walker SK, Brown GH, Nancarrow CD (1996a) The effects of an estrus-associated oviductal glycoprotein on the in vitro fertilization and development of ovine oocytes matured in vitro.
Theriogenology 46:1379-1388. https://doi.org/10.1016/S0093691X(96)00317-2

Hill JL, Walker SK, Brown GH, Nancarrow CD (1996b) The effects of an ovine oviductal estrus-associated glycoprotein on early embryo development. Theriogenology 46:1367-1377. https:// doi.org/10.1016/S0093-691X(96)00316-0

Hill JL, Wade MG, Nancarrow CD et al (1997) Influence of ovine oviducal amino acid concentrations and an ovine oestrus-associated glycoprotein on development and viability of bovine embryos. Mol Reprod Dev 47:164-169. https://doi.org/10.1002/(SICI) 1098-2795(199706)47:2\%3c164::AID-MRD6\%3e3.0.CO;2-K

Hribal R, Hachen A, Jewgenow K et al (2014) The influence of recombinant feline oviductin on different aspects of domestic cat (Felis catus) IVF and embryo quality. Theriogenology 82:742-749. https://doi.org/10.1016/j.theriogenology.2014.06.009

Huang Q-S, Xie X-L, Liang G et al (2012) The GH18 family of chitinases: their domain architectures, functions and evolutions. Glycobiology 22:23-34. https://doi.org/10.1093/glycob/cwr092

Jaffe RC, Arias EB, O'Day-Bowman MB et al (1996) Regional distribution and hormonal control of estrogen-dependent oviductspecific glycoprotein messenger ribonucleic acid in the baboon (Papio anubis). Biol Reprod 55:421-426. https://doi.org/10. 1095/biolreprod55.2.421

Jin SK, Yang WX (2017) Factors and pathways involved in capacitation: how are they regulated? Oncotarget 8:3600-3627. https:// doi.org/10.18632/oncotarget.12274

Kan FW, Esperanzate PW (2006) Surface mapping of binding of oviductin to the plasma membrane of golden hamster spermatozoa during in vitro capacitation and acrosome reaction. Mol Reprod Dev 73:756-766. https://doi.org/10.1002/mrd.20459

Kan FW, Roux E (1995) Elaboration of an oviductin by the oviductal epithelium in relation to embryo development as visualized by immunocytochemistry. Microsc Res Tech 31:478-487. https:// doi.org/10.1002/jemt.1070310604

Kan FWK, St. Jacques S, Bleau G (1989) Immunocytochemical evidence for the transfer of an oviductal antigen to the zona pellucida of hamster ova after ovulation. Biol Reprod 40:585-598. https://doi.org/10.1095/biolreprod40.3.585

Kan FW, Roux E, St-Jacques S, Bleau G (1990) Demonstration by lectin-gold cytochemistry of transfer of glycoconjugates of oviductal origin to the zona pellucida of oocytes after ovulation in hamsters. Anat Rec 226:37-47. https://doi.org/10.1002/ar.10922 60106

Kan FW, Roux E, Bleau G (1993) Immunolocalization of oviductin in endocytic compartments in the blastomeres of developing embryos in the golden hamster. Biol Reprod 48:77-88

Kapur RP, Johnson LV (1985) An oviductal fluid glycoprotein associated with ovulated mouse ova and early embryos. Dev Biol 112:89-93. https://doi.org/10.1016/0012-1606(85)90122-8

Kapur RP, Johnson LV (1986) Selective sequestration of an oviductal fluid glycoprotein in the perivitelline space of mouse oocytes and embryos. J Exp Zool 238:249-260. https://doi.org/10.1002/ jez.1402380215

Killian G (2004) Evidence for the role of oviduct secretions in sperm function, fertilization and embryo development. Anim Reprod Sci 82-83:141-153. https://doi.org/10.1016/j.anireprosci.2004. 04.028

King RS, Anderson SH, Killian GJ (1994) Effect of bovine oviductal estrus-associated protein on the ability of sperm to capacitate and fertilize oocytes. J Androl 15:468-478. https://doi.org/10.1002/j. 1939-4640.1994.tb00482.x

Komiya H, Onuma T, Hiroi M, Araki Y (1996) In situ localization of messenger ribonucleic acid for an oviduct-specific glycoprotein during various hormonal conditions in the golden hamster. Biol 
Reprod 55:1107-1118. https://doi.org/10.1095/biolreprod55.5. 1107

Kouba AJ, Abeydeera LR, Alvarez IM et al (2000) Effects of the porcine oviduct-specific glycoprotein on fertilization, polyspermy, and embryonic development in vitro. Biol Reprod 63:242-250. https://doi.org/10.1095/biolreprod63.1.242

Laheri S, Ashary N, Bhatt P, Modi D (2018) Oviductal glycoprotein 1 (OVGP1) is expressed by endometrial epithelium that regulates receptivity and trophoblast adhesion. J Assist Reprod Genet 35:1419-1429. https://doi.org/10.1007/s10815-018-1231-4

Lapensée L, Paquette Y, Bleau G (1997) Allelic polymorphism and chromosomal localization of the human oviductin gene (MUC9). Fertil Steril 68:702-708. https://doi.org/10.1016/S0015-0282(97) 00317-8

Leveille MC, Roberts KD, Chevalier S et al (1987) Uptake of an oviductal antigen by the hamster zona pellucida. Biol Reprod 36:227-238. https://doi.org/10.1095/biolreprod36.1.227

Lippes J, Wagh PV (1989) Human oviductal fluid (hOF) proteins. IV. Evidence for hOF proteins binding to human sperm. Fertil Steril 51:89-94. https://doi.org/10.1016/S0015-0282(16)60434-X

Lishko PV, Botchkina IL, Kirichok Y (2011) Progesterone activates the principal $\mathrm{Ca}^{2+}$ channel of human sperm. Nat 471:387-392

Lok IH, Briton-Jones CM, Yuen PM, Haines CJ (2002) Variable expression of oviductin mRNA at different stages of human reproductive cycle. J Assist Reprod Genet 19:569-576

Luconi M, Porazzi I, Ferruzzi P et al (2005) Tyrosine phosphorylation of the A kinase anchoring protein 3 (AKAP3) and soluble adenylate cyclase are involved in the increase of human sperm motility by bicarbonate. Biol Reprod 72:22-32. https://doi.org/ 10.1095/biolreprod.104.032490

Maines-Bandiera S, Woo MM, Borugian M et al (2010) Oviductal glycoprotein (OVGP1, MUC9): a differentiation-based mucin present in serum of women with ovarian cancer. Int J Gynecol Cancer 20:16-22. https://doi.org/10.1111/IGC.0b013e3181bcc96d

Malayer JR, Hansen PJ, Buhi WC (1988) Secretion of proteins by cultured bovine oviducts collected from estrus through early diestrus. J Exp Zool 248:345-353. https://doi.org/10.1002/jez. 1402480313

Malette B, Bleau G (1993) Biochemical characterization of hamster oviductin as a sulphated zona pellucida-binding glycoprotein. Biochem J 295:437-445. https://doi.org/10.1042/bj2950437

Malette B, Filion B, St-Jacques S et al (1995a) Hormonal control of the biosynthesis of hamster oviductin. Microsc Res Tech 31:470 477. https://doi.org/10.1002/jemt.1070310603

Malette B, Paquette Y, Merlen Y, Bleau G (1995b) Oviductins possess chitinase- and mucin-like domains: a lead in the search for the biological function of these oviduct-specific ZP-associating glycoproteins. Mol Reprod Dev 41:384-397. https://doi.org/10. 1002/mrd.1080410315

Martoglio AM, Kan FWK (1996) Immunohistochemical localization of oviductin in the endometrial lining of the golden hamster (Mesocricetus auratus) during the estrous cycle and early gestation. Histochem J 28:449-459. https://doi.org/10.1007/BF02331436

Martus NS, Verhage HG, Mavrogianis PA, Thibodeaux JK (1998) Enhancement of bovine oocyte fertilization in vitro with a bovine oviductal specific glycoprotein. J Reprod Fertil 113:323-329

McBride DS, Boisvert C, Bleau G, Kan FW (2004a) Evidence for the regulation of glycosylation of golden hamster (Mesocricetus auratus) oviductin during the estrous cycle. Biol Reprod 70:198203. https://doi.org/10.1095/biolreprod.103.020305

McBride DS, Boisvert C, Bleau G, Kan FW (2004b) Detection of nascent and/or mature forms of oviductin in the female reproductive tract and post-ovulatory oocytes by use of a polyclonal antibody against recombinant hamster oviductin. J Histochem Cytochem 52:1001-1009. https://doi.org/10.1369/jhc.3A6201.2004
McCauley TC, Buhi WC, Wu GM et al (2003) Oviduct-specific glycoprotein modulates sperm-zona binding and improves efficiency of porcine fertilization in vitro. Biol Reprod 69:828-834. https:// doi.org/10.1095/biolreprod.103.016444

Miller MR, Mannowetz N, Iavarone AT et al (2016) Unconventional endocannabinoid signaling governs sperm activation via the sex hormone progesterone. Sci 352:555-559

O'Day-Bowman MB, Mavrogianis PA, Fazleabas AT, Verhage HG (1995) A human oviduct-specific glycoprotein: synthesis, secretion, and localization during the menstrual cycle. Microsc Res Tech 32:57-69. https://doi.org/10.1002/jemt.1070320106

O’Day-Bowman MB, Mavrogianis P, Reuter LM et al (1996) Association of oviduct-specific glycoproteins with human and baboon (Papio anubis) ovarian oocytes and enhancement of human sperm binding to human hemizonae following in vitro incubation. Biol Reprod 54:60-69. https://doi.org/10.1095/biolreprod 54.1.60

O'Day-Bowman MB, Mavrogianis PA, Minshall RD, Verhage HG (2002) In vivo versus in vitro oviductal glycoprotein (OGP) association with the zona pellucida $(\mathrm{ZP})$ in the hamster and baboon. Mol Reprod Dev 62:248-256. https://doi.org/10.1002/mrd.10091

Oliphant G, Ross PR (1982) Demonstration of production and isolation of three sulfated glycoproteins from the rabbit oviduct. Biol Reprod 26:537-544. https://doi.org/10.1095/biolreprod26.3.537

Oliphant G, Reynolds AB, Smith PF et al (1984) Immunocytochemical localization and determination of hormone-induced synthesis of the sulfated oviductal glycoproteins. Biol Reprod 31:165-174. https://doi.org/10.1095/biolreprod31.1.165

Ooi A, Wong A, Esau L et al (2016) A guide to transient expression of membrane proteins in HEK-293 cells for functional characterization. Front Physiol 7:300. https://doi.org/10.3389/fphys. 2016.00300

Paquette Y, Merlen Y, Malette B, Bleau G (1995) Allelic polymorphism in the hamster oviductin gene is due to a variable number of mucin-like tandem repeats. Mol Reprod Dev 42:388-396. https://doi.org/10.1002/mrd.1080420404

Pereira R, Sá R, Barros A, Sousa M (2017) Major regulatory mechanisms involved in sperm motility. Asian J Androl 19:5-14. https://doi.org/10.4103/1008-682X.167716

Poersch A, Grassi ML, de Carvalho VP et al (2016) A proteomic signature of ovarian cancer tumor fluid identified by high throughput and verified by targeted proteomics. J Proteomics 145:226-236. https://doi.org/10.1016/j.jprot.2016.05.005

Pradeep MA, Jagadeesh J, De AK et al (2011) Purification, sequence characterization and effect of goat oviduct-specific glycoprotein on in vitro embryo development. Theriogenology 75:1005-1015. https://doi.org/10.1016/j.theriogenology.2010.11.007

Puga Molina LC, Luque GM, Balestrini PA et al (2018) Molecular basis of human sperm capacitation. Front Cell Dev Biol 6:1-23. https://doi.org/10.3389/fcell.2018.00072

Rahman MS, Kwon WS, Pang MG (2014) Calcium influx and male infertility in the context of the sperm proteome: an update. Biomed Res Int. https://doi.org/10.1155/2014/841615

Robitaille G, St-Jacques S, Potier M, Bleau G (1988) Characterization of an oviductal glycoprotein associated with the ovulated hamster oocyte. Biol Reprod 38:687-694. https://doi.org/10.1095/biolr eprod38.3.687

Roux E, Kan FWK (1995) Stage-specific immunolabeling for oviductin in the secretory granules of the oviductal epithelium of the golden hamster during the estrous cycle. Anat Rec 241:369-376. http://doi.org/10.1002/ar.1092410311

Roux E, Bleau G, Kan FWK (1997) Fate of hamster oviductin in the oviduct and uterus during early gestation. Mol Reprod Dev 46:306-317. https://doi.org/10.1002/(SICI)1098-2795(199703) 46:3\%3c306::AID-MRD9\%3e3.0.CO;2-T 
Saccary L, She Y-M, Oko R, Kan FWK (2013) Hamster oviductin regulates tyrosine phosphorylation of sperm proteins during in vitro capacitation. Biol Reprod 89:1-11. https://doi.org/10. 1095/biolreprod.113.109314

Saint-Dizier M, Marnier C, Tahir MZ et al (2014) OVGP1 is expressed in the canine oviduct at the time and place of oocyte maturation and fertilization. Mol Reprod Dev 81:972-982. https://doi.org/ $10.1002 / \mathrm{mrd} .22417$

Satoh T, Abe H, Sendai Y et al (1995) Biochemical characterization of a bovine oviduct-specific sialo-glycoprotein that sustains sperm viability in vitro. Biochim Biophys Acta Mol Cell Res 1266:117-123. https://doi.org/10.1016/0167-4889(94)00208-V

Schmidt A, Mavrogianis PA, O’Day-Bowman MB, Verhage HG (1997) Species-specific effect of oviductal glycoproteins on hamster sperm binding to hamster oocytes. Mol Reprod Dev 46:201-207. https://doi.org/10.1002/(SICI)1098-2795(199702)46:2\%3c201:: AID-MRD10\%3e3.0.CO;2-3

Sendai Y, Abe H, Kikuchi M et al (1994) Purification and molecular cloning of bovine oviduct-specific glycoprotein. Biol Reprod 50:927-934. https://doi.org/10.1095/biolreprod50.4.927

Sendai Y, Komiya H, Suzuki K et al (1995) Molecular cloning and characterization of a mouse oviduct-specific glycoprotein. Biol Reprod 53:285-294. https://doi.org/10.1095/biolreprod53.2.285

Simpson JL (2014) Birth defects and assisted reproductive technologies. Semin Fetal Neonatal Med 19:177-182. https://doi.org/10. 1016/j.siny.2014.01.001

Slayden OD, Friason FKE, Bond KR, Mishler EC (2018) Hormonal regulation of oviductal glycoprotein 1 (OVGP1; MUC9) in the rhesus macaque cervix. J Med Primatol 47:362-370. https://doi. org/10.1111/jmp. 12357

Soleilhavoup C, Riou C, Tsikis G et al (2016) Proteomes of the female genital tract during the oestrous cycle. Mol Cell Proteomics 15:93-108. https://doi.org/10.1074/mcp.M115.052332

St-Jacques S, Bleau G (1988) Monoclonal antibodies specific for an oviductal component associated with the hamster zona pellucida. J Reprod Immunol 12:247-261. https://doi.org/10.1016/01650378(88)90011-3

Sutton R, Nancarrow CD, Wallace AL, Rigby NW (1984) Identification of an oestrus-associated glycoprotein in oviducal fluid of the sheep. J Reprod Fertil 72:415-422. https://doi.org/10.1530/ jrf.0.0720415

Sutton R, Nancarrow CD, Wallace AL (1986) Oestrogen and seasonal effects on the production of an oestrus-associated glycoprotein in oviducal fluid of sheep. J Reprod Fertil 77:645-653. https:// doi.org/10.1530/jrf.0.0770645

Suzuki K, Sendai Y, Onuma T et al (1995) Molecular characterization of a hamster oviduct-specific glycoprotein. Biol Reprod 53:345-354

Suzuki H, Saito Y, Kagawa N, Yang X (2003) In vitro fertilization and polyspermy in the pig: factors affecting fertilization rates and cytoskeletal reorganization of the oocyte. Microsc Res Tech 61:327-334. https://doi.org/10.1002/jemt.10345

Thomas P, Smart TG (2005) HEK293 cell line: a vehicle for the expression of recombinant proteins. J Pharmacol Toxicol Methods 51:187-200. https://doi.org/10.1016/j.vascn.2004.08.014

van der Westerlaken L, Helmerhorst F, Dieben S, Naaktgeboren N (2005) Intracytoplasmic sperm injection as a treatment for unexplained total fertilization failure or low fertilization after conventional in vitro fertilization. Fertil Steril 83:612-617. https://doi. org/10.1016/j.fertnstert.2004.08.029
Verhage HG, Fazleabas AT, Donnelly K (1988) The in vitro synthesis and release of proteins by the human oviduct. Endocrinology 122:1639-1645. https://doi.org/10.1210/endo-122-4-1639

Verhage HG, Boice ML, Mavrogianis P et al (1989) Immunological characterization and immunocytochemical localization of oviduct-specific glycoproteins in the baboon (Papio anubis). Endocrinology 124:2464-2472. https://doi.org/10.1210/ endo-124-5-2464

Verhage HG, Mavrogianis PA, Boice ML et al (1990) Oviductal epithelium of the baboon: hormonal control and the immunogold localization of oviduct-specific glycoproteins. Am J Anat 187:81-90. https://doi.org/10.1002/aja.1001870109

Verhage HG, Mavrogianis PA, Boomsma RA et al (1997) Immunologic and molecular characterization of an estrogen-dependent glycoprotein in the rhesus (Macaca mulatta) oviduct. Biol Reprod 57:525-531. https://doi.org/10.1095/biolreprod57.3.525

Verhage HG, Mavrogianis PA, O'Day-Bowman MB et al (1998) Characteristics of an oviductal glycoprotein and its potential role in the fertilization process. Biol Reprod 58:1098-1101. https://doi. org/10.1095/biolreprod58.5.1098

Woo MMM, Gilks CB, Verhage HG et al (2004) Oviductal glycoprotein, a new differentiation-based indicator present in early ovarian epithelial neoplasia and cortical inclusion cysts. Gynecol Oncol 93:315-319. https://doi.org/10.1016/j.ygyno.2004.01.047

Wu R, Zhai Y, Kuick R et al (2016) Impact of oviductal versus ovarian epithelial cell of origin on ovarian endometrioid carcinoma phenotype in the mouse. J Pathol 240:341-351. https://doi.org/ 10.1002/path.4783

Wurm FM (2004) Production of recombinant protein therapeutics in cultivated mammalian cells. Nat Biotechnol 22:1393-1398. https://doi.org/10.1038/nbt1026

Yang X, Tao S, Orlando R et al (2012) Structures and biosynthesis of the $\mathrm{N}$ - and $\mathrm{O}$-glycans of recombinant human oviduct-specific glycoprotein expressed in human embryonic kidney cells. Carbohydr Res 358:47-55. https://doi.org/10.1016/j.carres.2012. 05.027

Yang X, Zhao Y, Yang X, Kan FWK (2015) Recombinant hamster oviductin is biologically active and exerts positive effects on sperm functions and sperm-oocyte binding. PLoS ONE 10:e0123003. https://doi.org/10.1371/journal.pone.0123003

Yong P, Gu Z, Luo JP et al (2002) Antibodies against the C-terminal peptide of rabbit oviductin inhibit mouse early embryo development to pass 2-cell stage. Cell Res 12:69-78. https://doi.org/10. 1038/sj.cr.7290112

Young SAM, Miyata H, Satouh Y et al (2016) CABYR is essential for fibrous sheath integrity and progressive motility in mouse spermatozoa. J Cell Sci 129:4379-4387. https://doi.org/10.1242/ jcs. 193151

Zhao Y, Kan FWK (2019) Human OVGP1 enhances tyrosine phosphorylation of proteins in the fibrous sheath involving AKAP3 and increases sperm-zona binding. J Assist Reprod Genet 36:13631377. https://doi.org/10.1007/s10815-019-01502-0

Zhao Y, Yang X, Jia Z et al (2016) Recombinant human oviductin regulates protein tyrosine phosphorylation and acrosome reaction. Reproduction 152:561-573. https://doi.org/10.1530/ REP-16-0177

Publisher's Note Springer Nature remains neutral with regard to jurisdictional claims in published maps and institutional affiliations. 